\title{
Impact of resolution on large-eddy simulation of midlatitude summertime convection
}

\author{
Christopher Moseley ${ }^{1,2}$, Ieda Pscheidt ${ }^{3}$, Guido Cioni ${ }^{1}$, and Rieke Heinze ${ }^{1}$ \\ ${ }^{1}$ Max Planck Institute for Meteorology, Hamburg, Germany \\ ${ }^{2}$ Department of Atmospheric Sciences, National Taiwan University, Taipei City, Taiwan \\ ${ }^{3}$ University of Bonn, Bonn, Germany
}

Correspondence: Christopher Moseley (christopher.moseley@ mpimet.mpg.de)

Received: 11 July 2019 - Discussion started: 20 August 2019

Revised: 6 January 2020 - Accepted: 27 January 2020 - Published: 10 March 2020

\begin{abstract}
We analyze life cycles of summertime moist convection of a large-eddy simulation (LES) in a limited-area setup over Germany. The goal is to assess the ability of the model to represent convective organization in space and time in comparison to radar data and its sensitivity to daily mean surface air temperature. A continuous period of $36 \mathrm{~d}$ in May and June 2016 is simulated with a grid spacing of $625 \mathrm{~m}$. This period was dominated by convection over large parts of the domain on most of the days. Using convective organization indices, and a tracking algorithm for convective precipitation events, we find that an LES with $625 \mathrm{~m}$ grid spacing tends to underestimate the degree of convective organization and shows a weaker sensitivity of heavy convective rainfall to temperature as suggested by the radar data. An analysis of $3 \mathrm{~d}$ with in this period that are simulated with a finer grid spacing of 312 and $156 \mathrm{~m}$ showed that a grid spacing at the $100 \mathrm{~m}$ scale has the potential to improve the simulated diurnal cycles of convection, the mean time evolution of single convective events, and the degree of convective organization.
\end{abstract}

Copyright statement. The author's copyright for this publication is transferred to the Max Planck Institute for Meteorology, Hamburg, Germany.

\section{Introduction}

An adequate representation of the diurnal cycles of convection in atmospheric models is important for numerical weather prediction and climate simulations, not only for the tropics (Ruppert and Hohenegger, 2018) but also for midlatitude summertime convection (Pritchard and Somerville, 2009). For this purpose, cloud-resolving models (CRMs) without deep cumulus parametrization are increasingly applied thanks to growing computational power. Meanwhile, the first global simulations with grid spacings between 7 and $2.5 \mathrm{~km}$ have been performed (Stevens et al., 2019). This range is usually termed convection permitting, as not all relevant processes within convective cells are sufficiently resolved. In fact, in some of these models shallow convection is parametrized in order to correct deficiencies in the simulation of smaller updrafts. Regional limited-area models allow for even higher resolutions with grid spacings in the sub-kilometer range with large-eddy simulations (LESs) where the large eddies of the turbulence spectrum are modeled explicitly as opposed to a fully parametrized turbulence spectrum in the convection-permitting simulations. Recently, selected diurnal cycles over Germany have been simulated in a realistic LES setup with the model ICON-LEM (Heinze et al., 2017) within the German funded project $\operatorname{HD}(C P)^{2}$ ("High Definition Clouds and Precipitation for advancing Climate Prediction"). Previous studies have discussed the question of which resolution is optimal for a good representation of the processes involved in deep convective updrafts. A semi-idealized study of days with precipitating convection by Petch et al. (2002) with grid spacings between $2 \mathrm{~km}$ and $125 \mathrm{~m}$ showed that the horizontal resolution should be at least 
one-quarter of the sub-cloud layer depth and that the best match with observational data was found only at the highest resolution. Similarly, a study by Bryan et al. (2003) showed that for an adequate simulation of a squall line using models with traditional LES closures, grid spacings of the order of $100 \mathrm{~m}$ are required. Besides horizontal resolution, there are also other factors that impact the ability of CRMs to simulate convection, such as the subgrid turbulence scheme (Panosetti et al., 2019), the microphysics scheme (Singh and O'Gorman, 2014), and the representation of the land surface.

The formation of strong convective precipitation events depends on several environmental conditions, like air temperature, surface fluxes, large-scale forcing, and the ability of convection to organize. The sensitivity of precipitation extremes to warmer temperatures has been heavily discussed in recent years. The argument that the strongest events should increase at a rate of ca. $7 \% \mathrm{~K}^{-1}$ according to the thermodynamic Clausius-Clapeyron (CC) relation was put forward by Allen and Ingram (2002) and Trenberth et al. (2003). Observational evidence showed that even in midlatitude regions, these rates can be up to twice the $\mathrm{CC}$ rate (Lenderink and Van Meijgaard, 2008; Westra et al., 2014), which is predominantly the case for convective precipitation, while the stratiform precipitation type follows CC more closely (Berg et al., 2013). Meanwhile, several studies have found a super-CC scaling for present-day climate. This indicates that beyond purely thermodynamic processes, the dynamic component within convective clouds also contributes to the intensification and has to be evaluated separately. However, it has to be mentioned that some studies have found a scaling that is close to the CC rate, like Ban et al. (2015), who argue that the super-CC scaling might be an artifact that results from the statistical methods applied to determine the scaling rate, e.g., the imposition of thresholds for wet days in the data analysis.

Analyses of climate change projections have indicated that while the thermodynamic contribution to the intensification of extreme precipitation is expected to be relatively homogeneous globally, there may be strong regional differences in the dynamic contribution due to changes in circulation patterns (Emori and Brown, 2005; Pfahl et al., 2017; Norris et al., 2019). CRMs should therefore also be able to simulate the time evolution of convective precipitation events and their interaction and organization among each other in a realistic way, to correctly represent their sensitivity to $2 \mathrm{~m}$ air temperature. Ban et al. (2014) have analyzed the temperature scaling of a decade-long simulation with $2.2 \mathrm{~km}$ grid spacing over Switzerland, and they found a good agreement with observations. Kendon et al. (2014) have found an intensification of hourly rainfall over Britain under a climate change scenario with a $1.5 \mathrm{~km}$ model. However, a correct representation of the temperature scaling of heavy rainfall becomes increasingly difficult with decreasing model resolution. Rasp et al. (2018) have shown that in principle subgrid cloud organization has to be included in stochastic cloud parametriza- tions. These parametrizations are particularly relevant at the abovementioned convection-permitting scale, and at present we assume a random cloud distribution within model grid cells.

Some studies that have investigated the sensitivity of convection to resolution distinguish between bulk convergence and structural convergence (Langhans et al., 2012; Panosetti et al., 2019): while the former is concerned with large-scale mean properties, the latter refers to an analysis of cloud sizes, cloud shapes, and convective organization. Our study mainly addresses structural convergence. To analyze the properties of convection and convective organization in model output and gridded observations like radar or satellite data, objectoriented methods are increasingly applied. Besides simple mean values and percentiles of precipitation intensities, they provide information on the spatial distribution of sizes and shapes of precipitation objects. Furthermore, several indices that are based on these methods have been developed over recent years and are capable of quantifying the degree of organization of the convection cells in space (Senf et al., 2018; Pscheidt et al., 2019). Using a combination of several convective organization indices that we also apply in the present study, Pscheidt et al. (2019) have shown that convective precipitation cores and cloud tops are organized most of the time over Germany.

However, the shortcoming of these methods is that they provide only information on the spatial distribution of convection objects, but not on their temporal evolution. Tracking methods are able to additionally capture the life cycles of the objects, and their interaction among each other. Several tracking methods for convective storms have been developed in the past, and although they are based on similar ideas they are specialized for different purposes, such as nowcasting thunderstorms (Dixon and Wiener, 1993; Hering et al., 2005; Kober and Tafferner, 2009; Wapler, 2017) and studying the cloud life cycle statistics in shallow (Heus and Seifert, 2013; Heiblum et al., 2016) and deep convection (Lochbihler et al., 2017; Moseley et al., 2019), or even larger structures like mesoscale convective systems (Fiolleau and Roca, 2013).

In this study, we apply the tracking method of Moseley et al. (2019), which provides statistical information on the interaction of convective precipitation objects among each other in terms of merging and splitting. We analyze convective diurnal cycles simulated by the ICON-LEM with grid spacings in the sub-kilometer range, and we assess the impact of horizontal resolution, and daily mean temperatures, on the simulated convection. This article is organized as follows: in Sect. 2 we describe the ICON-LEM setup, the radar dataset that is used for evaluation, and the object-oriented analysis methods. In Sect. 3, we compare the simulation results of three different model resolutions between 625 and $156 \mathrm{~m}$ grid spacing, and in Sect. 4 we analyze a continuous $36 \mathrm{~d}$ long simulation period with $625 \mathrm{~m}$ grid spacing. We discuss results in Sect. 5, and we present conclusions in Sect. 6. 


\section{Data and methods}

\subsection{Model configuration}

The simulations are performed with the unified modeling framework ICON, which was run with the LES physics package, in the following termed ICON-LEM ("ICON Large Eddy Model") (Dipankar et al., 2015). ICON is a nonhydrostatic new-generation model tailored to perform atmospheric simulations in different setups ranging from global climate reconstructions to limited-area nested configurations and idealized configurations. Different physics packages needed to parametrize sub-scale variability are adopted depending on the setup considered. ICON has been used at the German Weather Service (DWD) since 2015 to produce operational forecasts and has been successfully adopted as a tool to improve our understanding of moist convection in many areas of the world (e.g., Klocke et al., 2017).

In our work, ICON-LEM is used in a limited-area configuration to perform convection-explicit simulations over Germany. The model configuration follows the description given in Heinze et al. (2017) very closely, to which the reader is referred for further details on the parametrizations employed. We only emphasize that turbulence is parametrized using a Smagorinsky model (Dipankar et al., 2015) (thus, subgrid turbulence is treated as isotropic), the land surface is described using the TERRA-ML model (Schrodin and Heise, 2002), the surface layer is treated with a drag-law formulation following Louis (1979), a simple all-or-nothing cloud scheme is used, and cumulus convection as well as gravity waves (orographic and non-orographic) are not parametrized.

At the boundaries, ICON is forced by operational hourly analysis data by the previous operational numerical weather prediction (NWP) model COSMO-DE by the DWD, run with ca. $2.8 \mathrm{~km}$ grid spacing. The model output is interpolated to the ICON model grid with $625 \mathrm{~m}$ grid spacing, on which the model simulations are performed. Dynamical downscaling in a one-way nesting approach is applied on 3 of the model days, in a first step to $312 \mathrm{~m}$ and in a second step to $156 \mathrm{~m}$ grid spacing (Heinze et al., 2017). In this case, boundary conditions for each one of the two inner domains are taken from the relative outer domain (see Fig. 1).

We note that we restrict the evaluation of the ICON-LEM simulations to daytime between 06:00 and 21:00 UTC, since it is known that the nocturnal boundary layer is not sufficiently resolved at LES resolutions of $100 \mathrm{~m}$ and coarser, which may introduce unknown biases in cloud cover at night (van Stratum and Stevens, 2015). Therefore, the figures showing our results are also restricted to this period.

\subsection{Simulation period}

We chose a period of 36 continuous days, beginning on 26 May and ending on 20 June 2016. This period includes an exceptional sequence of severe weather events producing heavy convective precipitation, 10 tornadoes, and hail, which caused damages running into the billions of euros (Piper et al., 2016). The strongest events were concentrated between 26 and 29 May 2016 mostly over southern Germany, while during the first days of June a $\Omega$-blocking pattern over Europe prevented the typical westerly flow from reaching central Europe and enhanced local instability caused by diurnal surface heating and nocturnal cooling.

To reduce computational costs, the entire $36 \mathrm{~d}$ period is simulated only on the outermost nest (domain 1) with $625 \mathrm{~m}$ grid spacing. The simulation is initialized on 26 May 2016 at 00:00 UTC and continuously run through 31 June 2016, 00:00 UTC using only the forcing from the boundary conditions provided by hourly analysis of the COSMO-DE data at the lateral boundaries of the outer domain. Local features, such as individual clouds or thunderstorms, are mostly the results of local forcing and thus may look different from the observed ones, which is partially due to the inherent unpredictability of convection. A total of $3 \mathrm{~d}$ among this period are simulated with the additional nests with 312 and $156 \mathrm{~m}$ grid spacing (a more detailed description of the largescale situation in this period over Germany is given by Rasp et al. (2018), who analyzed the period between 26 May and 9 June 2016 in their study).

- 29 May 2016 was dominated mainly by wind from the southeast, with relatively widespread high level clouds that grew larger throughout the afternoon and strong convection over the largest part of the domain. At night, a mesoscale convective system developed that covered most of southern Germany.

- 3 June 2016 was characterized by moderate easterly wind in the northern half of the domain with mainly clear sky in the morning and broken convective cloudiness in the afternoon. The southern part of the domain was dominated by strong convective rainfall, beginning around noon.

- 6 June 2016 was characterized by weak easterly winds and a distinct diurnal cycle of convection with mainly clear sky in the morning and convective cloudiness with a maximum in the afternoon over the largest part of the domain, associated with increasing high-level cloudiness caused by stratiform outflow.

In all simulations, the state of the atmosphere and the soil has been initialized at 00:00 UTC with COSMO-DE data. The first 6 simulation hours are used as spin-up for the atmosphere and are removed from the analysis. For the highresolution three-domain simulations, all three nests are initiated at the same time.

\subsection{Preparation of model and radar data}

We use the RADOLAN RY C-Band weather radar composite provided by the German Weather Service (Bartels et al., 


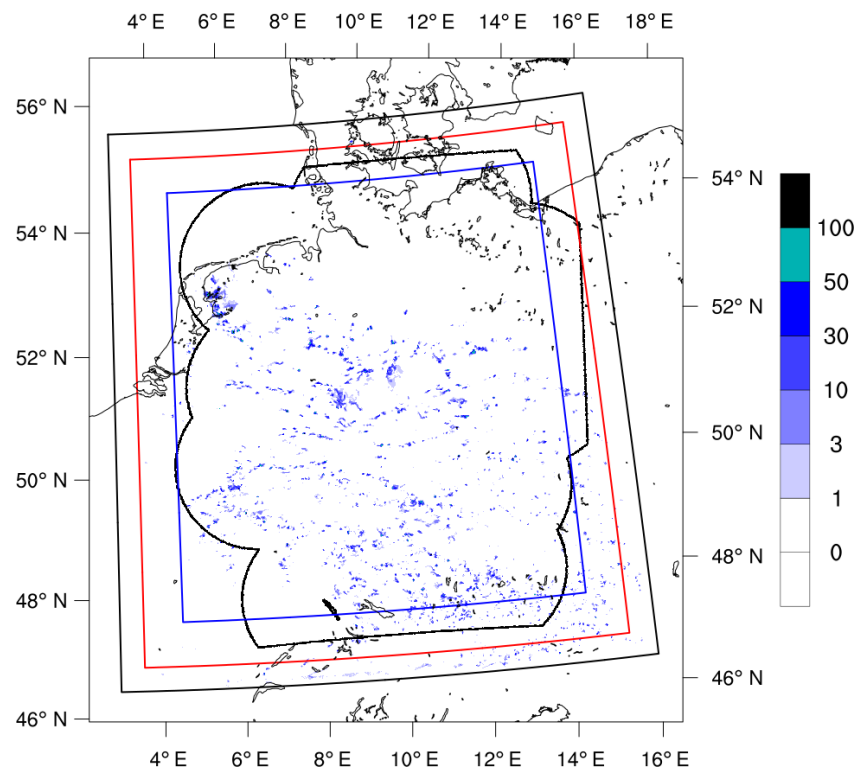

Figure 1. Simulation domain. The black frame shows the extent of the outer domain 1 with $625 \mathrm{~m}$ grid spacing, and the red and blue frames show the nested domains 2 and 3 with 312 and $156 \mathrm{~m}$ grid spacing, respectively. The black contour shows the maximum extent of the RADOLAN dataset. Color shading shows the surface precipitation field on 3 June 2016, at 14:00 UTC, simulated on the outer domain with $625 \mathrm{~m}$ grid spacing, given in millimeters per hour.

2004). This data product contains precipitation intensities derived from radar reflectivities on a grid of approximately $1 \mathrm{~km} \times 1 \mathrm{~km}$. We apply a conservative remapping to interpolate all model and radar data to a common lat-long grid. This implies that we also evaluate the model data on the three nests with 625,312 , and $156 \mathrm{~m}$ model grid spacing on the same target grid after interpolation. The main reason for interpolating the model data is that the original ICON-LEM output is given on an unstructured triangular grid which is difficult to handle for our post-processing tools. The second reason is that we prefer to compare the data of the three different model resolutions, and the radar data, on the same grid, to reach a fair comparison. We chose a $1 \times 1 \mathrm{~km}^{2}$ latlong grid, since this is roughly the resolution of the radar data. Further, it is only slightly coarser than the resolution of the coarse ICON-LEM resolution with $600 \mathrm{~m}$ grid spacing of the triangle edges. However, as the effective resolution of the ICON-LEM data is larger than the grid spacing, we can assume that there is no loss in resolution at least for the $600 \mathrm{~m}$ simulation. A similar regridding has also been used for other studies which also analyzed ICON-LEM output (Heinze et al., 2017; Pscheidt et al., 2019).

As the radar data contain areas of missing values that vary in time when instruments were switched on and off, we also mask out these areas in the model data, to have a one-toone comparison. In Sect. 3, where we compare results of all three nests, we restrict the domain to the innermost nest with
$156 \mathrm{~m}$ grid spacing as shown in Fig. 1. Elsewhere, where we analyze only the outer domain with $625 \mathrm{~m}$ grid spacing, we include the full domain size.

The temporal output interval of the model data is $2 \mathrm{~min}$, while the radar data are available with a 5 min interval. Therefore, the modeled precipitation intensities have been linearly time-interpolated to a $5 \mathrm{~min}$ interval.

\subsection{Indices of convective organization}

To investigate whether convective clouds tend to organize in space, we follow the approach used in Pscheidt et al. (2019): first, we detect signatures of convection in radar and model rain rates by applying a segmentation algorithm with a splitand-merge approach (Senf et al., 2018) with a threshold of $1 \mathrm{~mm} \mathrm{~h}^{-1}$. In a second step, we compute commonly used organization indices for the radar observations and the simulation output. The organization indices are based on the characteristics of the 2-D objects obtained from the segmentation algorithm. We employ three organization indices, namely the Simple Convective Aggregation Index (SCAI; Tobin et al., 2012) and the convective organization potential (COP; White et al., 2018), which are both based on all-neighbor distances, and the $I_{\text {org }}$ index (Tompkins and Semie, 2017), which uses a nearest-neighbor $(\mathrm{NN})$ distance approach. SCAI is defined as

$\mathrm{SCAI}=\frac{N D_{0}}{N_{\max } L} 1000$

where $N$ is the number of objects in the domain, $D_{0}$ is the geometric mean distance of the centroids between all possible pairs of objects, $N_{\max }$ is the possible maximum number of objects that can exist in the domain, and $L$ is the characteristic domain size. In this study, $N_{\max }$ is the total number of grid boxes in the domain, and $L$ is the southwest-northeast distance in the domain. The degree of organization increases as the SCAI decreases.

COP considers the interaction potential between two objects $V(i, j)=(\sqrt{A(i)}+\sqrt{A(j)}) /(d(i, j) \sqrt{\pi})$, where $A(i)$ is the area of object $i$ and $d(i, j)$ is the Euclidean distance between the centroids of the objects $i$ and $j$. COP is defined as

$\mathrm{COP}=\frac{\sum_{i=1}^{N} \sum_{j=i+1}^{N} V(i, j)}{\frac{1}{2} N(N-1)}$.

The degree of organization increases as COP increases.

Unlike SCAI and COP, which mainly quantify the degree of clustering, the NN-based organization index $I_{\text {org }}$ (Tompkins and Semie, 2017) is able to distinguish between three types of spatial distribution: clustered, regular, and random. In this approach, we treat objects as discs (similar to Nair et al., 1998), and we compute the cumulative distribution function of the NN edge-to-edge distances (NNCDF) and compare it to the NNCDF of theoretical randomly distributed 
objects over the same domain. The theoretical NNCDF is approximated by bootstrapping, in which a random number of objects with the observed size distribution are randomly placed over the domain (Weger et al., 1992; Nair et al., 1998). We perform 100 simulations and compare the observed NNCDF to the 100 theoretical NNCDFs in a graph. $I_{\text {org }}$ is defined as the area below such a comparison curve (for more details see, e.g., Pscheidt et al., 2019; Tompkins and Semie, 2017). From the 100 computed $I_{\text {org }}$ indices we select percentiles 2.5 and 97.5 to identify the spatial distribution. The objects are organized in clusters when percentile 2.5 is greater than 0.5 , whereas they present a regular distribution in space when percentile 97.5 is lower than 0.5. Otherwise, the scenario can not be differentiated from randomness.

In addition to the degree of convective organization, we also investigate the shape of the objects with the index $I_{\text {shape }}$ defined as

$I_{\text {shape }}=\frac{1}{N} \sum_{i=1}^{N} s(i)$,

where $s(i)=P_{\mathrm{eq}}(i) / P(i)$ is the shape ratio, $P(i)$ is the actual perimeter, and $P_{\mathrm{eq}}(i)=\sqrt{4 \pi A(i)}$ is the perimeter of an equivalent, area-equal disc of the object $i$. The perimeter $P(i)$ is computed as the contour line through the centers of the border grid boxes of the objects (Benkrid and Crookes, 2017; van der Walt et al., 2014). $I_{\text {shape }}$ ranges between 0 and 1 and indicates the predominant presence of linear shapes for the former and circular shapes for the latter. $I_{\text {shape }}$ close to 0.5 indicates predominance of elliptical shapes.

\subsection{Rain cell tracking}

We apply the "iterative rain cell tracking" (IRT) algorithm to track life cycles of convective precipitation events in space and time (Moseley et al., 2019). In a first step, precipitation objects are detected for each time step individually. They are defined as connected areas over a given threshold chosen as $1 \mathrm{~mm} \mathrm{~h}^{-1}$ surface precipitation intensity. This threshold has proven to generate reasonable results, and is on the order of the resolution threshold of the weather radar. For each object, the area and the mean surface precipitation intensity averaged over this area are recorded. The algorithm checks for overlaps of each object with objects in the previous and the subsequent time step, and records the concerning object identifiers. If an object overlaps with more than one object at the previous or subsequent time step, the two largest ones are recorded; others are ignored.

It sometimes happens that objects of subsequent time steps do not overlap although they belong to the same track, since they are advected by mean background flow, especially if the time step is relatively large and the objects are small. To correct this artifact, in a second step a mean background advection field is diagnosed and the procedure is repeated by taking into account the displacements of the objects due to the advection field while checking for overlaps. This step has to be iterated until the object identification result converges.

In a third step, overlapping objects are combined to tracks. A fraction of the tracks have distinct life cycles and do not merge with others or split up into fragments. They are initiated as new emerging precipitation events and eventually vanish when surface precipitation ceases. We call these tracks solitary. Tracks that experience merging and splitting are recorded separately. We call these tracks interacting. A parameter, the so-called termination sensitivity $\Theta$ that takes values between 0 and 1 , provides a criterion whether a merging or splitting event is recorded, or ignored. If $\Theta=0$, then every merging and splitting event will lead to a termination of all involved tracks and will be recorded as a track that interacts with its neighbors. In the other extreme $\Theta=1$, the largest object that experiences a merging or splitting event will always be continued and regarded as solitary, while the smaller involved tracks will be terminated and not regarded as non-solitary. If $\Theta$ takes intermediate values, all participating tracks will only terminate when they are of comparable size, otherwise the largest one will be regarded as solitary and the smaller one as interacting. For our analysis, we choose an intermediate value of $\Theta=0.5$.

\section{Impact of resolution}

\subsection{Domain mean precipitation and size distribution}

To analyze the impact of resolution on the simulated life cycles of convection, we make use of the $3 \mathrm{~d}$ which have been simulated on three nests with $625 \mathrm{~m}$ (DOM01), $312 \mathrm{~m}$ (DOM02), and $156 \mathrm{~m}$ (DOM03) grid spacing. Figure 2 shows the time series of the daily mean precipitation for each day for all three domains next to the radar data, averaged over all areas where radar data are available. While on 29 May the simulated precipitation amount for all three domains is very close and strongly mismatches the radar data, on the other $2 \mathrm{~d}$ on 3 and 6 June the time evolution of mean precipitation differs more strongly for the different resolutions. On the last $2 \mathrm{~d}$, the match with RADOLAN is better for higher resolutions: the peak precipitation on the $625 \mathrm{~m}$ domain is larger and is reached earlier than for the 312 and $156 \mathrm{~m}$ nests. Especially on 3 June, both the magnitude and the timing of the precipitation peak are closer to the radar data for the domains with higher resolutions than for the $625 \mathrm{~m}$ domain. On both 3 and 6 June, the strong increase in precipitation around 10:00 UTC is steeper than in the radar data for $625 \mathrm{~m}$, while the slope matches the radar data best for $156 \mathrm{~m}$. However, on 6 June the decline of precipitation intensity in the late afternoon and evening hours appears too late. We note that although the later onset in the simulations with higher resolution appears to be consistent on 3 and 6 June, we cannot rule out that some of the other differences may be due to internal variability, like individual large storms. Simulated 
cloud water follows the total precipitation intensity closely on the days 29 May and 6 June, while the high values of liquid water path (LWP) in the morning hours on 3 June indicate non-precipitating cloudiness, which was found mainly in the southern part of the domain.

Rain cell size distributions for all three nests and RADOLAN are shown in Fig. 3, including the rain cell objects of all three-domain days. Compared to the $625 \mathrm{~m}$ nest, the RADOLAN data show a larger fraction of large objects, but fewer small objects that can be attributed to isolated cells. However, the total number of large clouds in the radar data is not much different from the simulations. For the more highly resolved nests, the fraction of small objects is closer to radar. This picture is consistent if the size distribution is plotted for each of the days individually (not shown).

\subsection{Convective organization indices}

A general convergence of the higher-resolution nests to the RADOLAN data is found not only in the diurnal cycles of mean precipitation and the cell size distribution, but also in the organization indices that we have calculated for the three domains and the RADOLAN data, especially in SCAI and $I_{\text {shape }}$ (Fig. 4). In general, SCAI tends to follow the mean precipitation intensity, rather than the mean amount of cloud water (Fig. 2). The analysis of SCAI reveals that on 29 May the radar objects are more clustered than the simulated ones (Fig. 4a); however, the finest nest is closest to RADOLAN. The $156 \mathrm{~m}$ nest also shows the best performance on 6 June, when the degree of organization of observed objects is very well represented at $156 \mathrm{~m}$ (Fig. 4c). The situation is, however, different for 3 June (Fig. 4b). Before 12:00 UTC the finer nests best represent the degree of organization, whereas from 12:00 until 18:00 UTC, the coarsest nest is in better agreement with radar. On all $3 \mathrm{~d}$, SCAI shows a clear increase in the degree of clustering with the nest's resolution, which is due to the decrease in the number of small objects as the grid spacing increases (see the size distribution in Fig. 3). Although the size distribution does not provide any direct information on the shape of objects, the smaller value of $I_{\text {shape }}$ in the radar data is consistent with the larger fraction of large objects, since large objects are more likely to deviate strongly from the circular shape (Fig. $4 \mathrm{j}-1$ ).

The COP index indicates more clustering of the radar objects than in the simulations in the course of the days, especially on 29 May and 3 June, due to the smaller sizes of the simulated objects (Fig. 4d, e; note also the size distributions in Fig. 3). A clustered distribution is also reinforced by $I_{\text {org }}$ (Fig. $4 \mathrm{~g}-\mathrm{i}$ ), indicating convective organization throughout the day with a slight decrease in the degree of clustering in the afternoon in agreement with SCAI and COP. The simulations represent $I_{\text {org }}$ in all three grid spacings well, and significant differences among the three grid spacings are not found. In contrast, the shape of the objects is best represented for the $156 \mathrm{~m}$ nest for the days 29 May and 3 June, with decreasing performance for the coarser nests (Fig. $4 \mathrm{j}, \mathrm{k}$ ).

For 6 June, the diurnal cycle of the COP and $I_{\text {org }}$ shows a different behavior than on the other $2 \mathrm{~d}$ : COP is in good agreement with radar between 09:00 and 17:00 UTC for all three grid spacings (Fig. 4f). In the evening, however, the simulations with the finest nests reveal larger object sizes (not shown) than observed in radar, leading to an overestimation of the degree of clustering. Besides, no objects are detected in the $625 \mathrm{~m}$ nest after 19:00 UTC. The increased oscillation in the degree of clustering after 20:00 UTC seen in COP is reflected in $I_{\text {org }}$ and indicates spatial distributions varying between clustering and random distribution (Fig. 4i). Regarding the object's shapes, the coarsest nest shows the best performance for this day, though (Fig. 41).

An interesting observation is that SCAI differs more strongly between the days, while for the other indices, the differences among the simulation nests and the radar data are of the same order as the differences between different days. The reason could be that SCAI closely follows the total number of rain cells, which varies strongly between days, while the other indices are rather linked to the size distribution, which is similar on all $3 \mathrm{~d}$.

\subsection{Track statistics}

We apply the tracking algorithm to the precipitation cells of model and RADOLAN data (note that all data are evaluated on the domain of the innermost nest and on the same grid), and we build a single sample containing all tracks of the $3 \mathrm{~d}$. In total, the algorithm detects 141682 tracks for DOM01, 160042 tracks for DOM02, and 124820 for DOM03, showing no clear trend with resolution. For the radar data, a smaller number of 67657 tracks is detected. We perform a separate analysis for solitary tracks (i.e., tracks that do not merge or split), tracks that involve only merging (i.e., tracks that either merge into others or are initiated by merging of other tracks, but that do not involve splitting), tracks that involve only splitting (i.e., tracks that split up, or tracks that are initiated as a fragment of a splitting event), and tracks that involve both merging and splitting (i.e., tracks that either are initiated as a merging event and split up later or are initiated as a fragment and later merge again with other tracks); see Table 1. Although less than $10 \%$ of the total rainfall is generated by solitary tracks (excluding drizzle below the threshold of $1 \mathrm{~mm} \mathrm{~h}^{-1}$ and tracks that touch the boundaries), there is a strong variation in the contribution of solitary tracks to the total rainfall, namely $9.4 \%, 7.1 \%$, and $4.2 \%$, indicating the tendency toward more organization with increasing resolution. For comparison, for RADOLAN we find a fraction of $6.7 \%$, which is between the model results of the 312 and $156 \mathrm{~m}$ nest. The ratio of the number of tracks belonging to all track types is very similar for all nests and matches well with RADOLAN, but there are differences in the contribution to total rainfall among these types. There is a clear increase with 

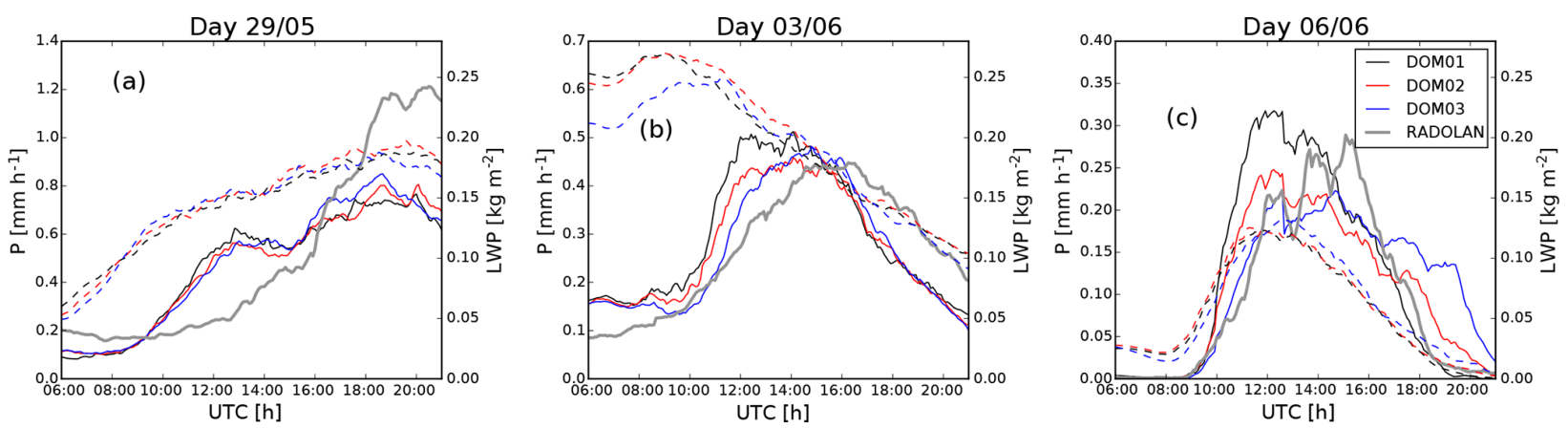

Figure 2. Time series of the mean precipitation intensity $P$ (solid lines, left axes) and liquid water path LWP (dashed lines, right axes), for the $3 \mathrm{~d} 29$ May (a), 3 June (b), and 6 June (c), for all three domains with $625 \mathrm{~m}$ (DOM01), $312 \mathrm{~m}$ (DOM02), and 156 m (DOM03) grid spacing. The gray thick line shows the RADOLAN derived precipitation intensity. Averaging was carried out over all grid boxes where radar data are available.
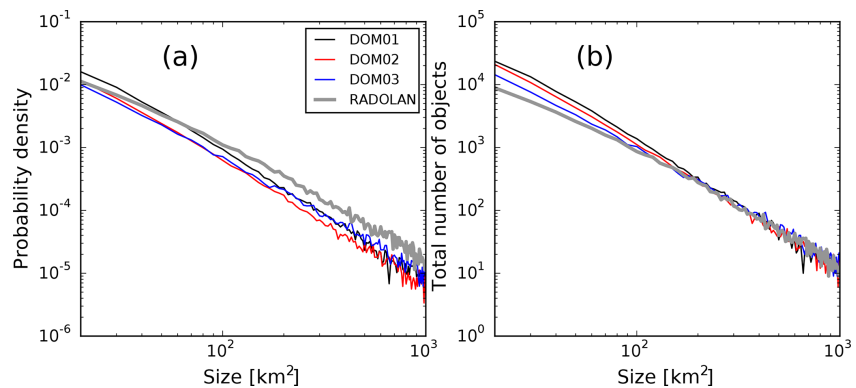

Figure 3. (a) Normalized probability density function (PDF) of rain cell size distributions, on all three domains DOM01, DOM02, and DOM03 and the RADOLAN data. (b) Same as (a), but with total number of cells on the vertical axis (in bins of width $10 \mathrm{~km}^{2}$ ). The PDF includes all rain cells between 06:00 and 21:00 UTC on all $3 \mathrm{~d}$ (29 May, 3 June, 6 June).

resolution from $29.5 \%$ (for DOM01) to $47.2 \%$ (DOM03) for the type that experiences both merging and splitting. As this track type can be regarded as the one that experiences the strongest interaction with neighboring tracks, the high rainfall ratio falling onto this track type in the $156 \mathrm{~m}$ nest indicates a stronger impact of convective organization. However, for RADOLAN, this ratio is only $32.4 \%$, which is close to the coarse-resolution result.

Even though solitary tracks contribute to less than $10 \%$ of the total precipitation, they are most suited for an analysis of the time evolution of convective rainfall events. Therefore, we have a closer look at the performance of the model to simulate solitary track life cycles. Mean life cycle composites of the 3 three-domain days, comparing model and RADOLAN tracks and conditioned on short (20-40 min), intermediate (50-70 $\mathrm{min})$, and long (80-100 $\mathrm{min})$ track durations, are shown in Fig. 5. The curves show that generally the mean peak intensities decrease for higher resolutions, while the largest jump is visible between 312 and $156 \mathrm{~m}$ grid spacing (Fig. 5a-c). The match with RADOLAN intensities is best for the $156 \mathrm{~m}$ nest. The track sizes do not show an im- provement with increasing resolution compared to the radar data: sizes are smaller in the model data than in RADOLAN, except for short-duration tracks in the $625 \mathrm{~m}$ domain. In contrast to intensity, track maximum extents of the $625 \mathrm{~m}$ domain show a better match with RADOLAN, while the sizes of tracks of the $312 \mathrm{~m}$ and $156 \mathrm{~m}$ nests are clearly smaller (Fig. $5 \mathrm{~d}-\mathrm{f}$ ). The rate of total precipitation produced by the solitary rainfall events (i.e., the spatial integral of precipitation intensity integrated over the object area shown in Fig. 5g-i), however, shows that for intermediate- and longduration tracks simulated with $625 \mathrm{~m}$ grid spacing, the too large intensities are compensated for by the too small intensities, resulting in a good match with RADOLAN, while rates are clearly too small for the finer nests. Only for the shortduration tracks, does the precipitation rate of the $156 \mathrm{~m}$ nest agree with RADOLAN, while the coarse resolution produces too much precipitation.

We further visualize the statistics of the solitary track peak intensities, the maximal effective radii of the objects (where the effective radius is given as $r_{i}=\sqrt{A_{i} / \pi}$, with $A_{i}$ being the area of object $i$ ), and the total precipitation amount produced by the tracks (given as the spatial integral over the area and the temporal integral along the track duration of the local intensity) in the box-and-whisker plots in Fig. 6. The solid curves in Fig. 6a show that in total there are more solitary tracks found in the model data than in RADOLAN, but for longer durations, curves for RADOLAN and the $156 \mathrm{~m}$ nest converge. The decreased number of longer-lasting solitary tracks reflects the stronger organization in the highresolution domain, since stronger convective events are more likely to interact with neighboring tracks. As already indicated by the life cycles in Fig. 5, we see that the median of peak intensities is lowest for the finest resolution and shows a good match with RADOLAN, while peak intensities reach higher values for the $625 \mathrm{~m}$ domain. However, the spread in peak intensities is much higher for the RADOLAN data for longer-duration tracks, while it is lowest for the $156 \mathrm{~m}$ nest, a feature that is not visible in the mean life cycles in Fig. 5. Fur- 

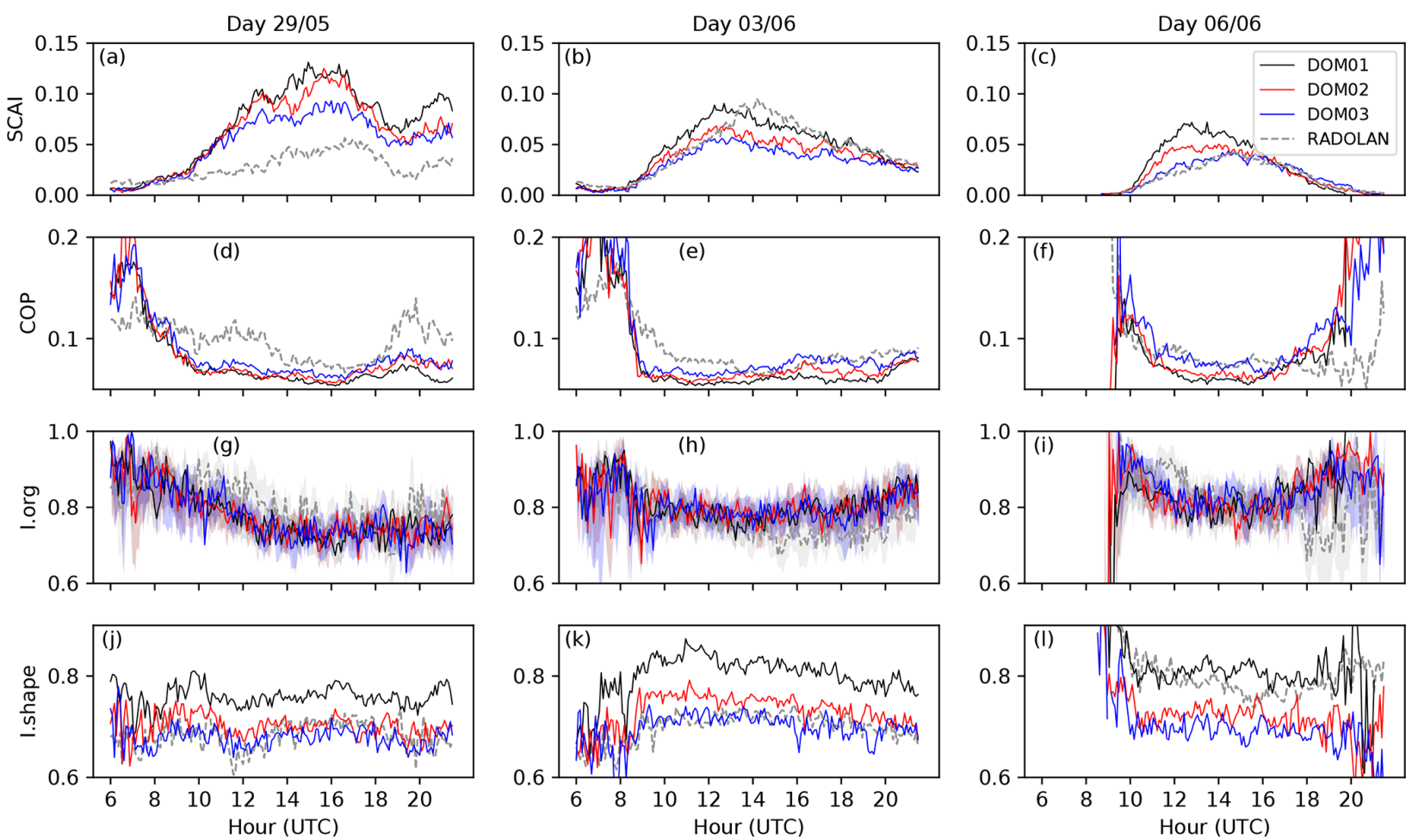

Figure 4. Convective organization indices SCAI (a-c), COP (d-f), median $I_{\text {org }}(\mathbf{g}-\mathbf{i})$, and $I_{\text {shape }}(\mathbf{j}-\mathbf{l})$ for the days 29 May and 3 and 6 June 2016, for the three nests with $625 \mathrm{~m}$ (DOM01), $312 \mathrm{~m}$ (DOM02), and $156 \mathrm{~m}$ (DOM03) grid spacing and the RADOLAN data. Averaging was carried out over all grid boxes within the $156 \mathrm{~m}$ nest where radar data are available.

Table 1. Ratio of the number of tracks of given track types (solitary, tracks that involve only merging, tracks that involve only splitting, and tracks involving both merging and splitting) and the total amount of rainfall that they contribute, relative to the total number and rainfall amount, respectively, of all tracks. Note that tracks that touch the domain boundaries are removed from the analysis. Fractions (in percent), including all 3 three-domain days, are given for all three domains with $625 \mathrm{~m}$ (DOM01), $312 \mathrm{~m}$ (DOM02), and 156 m (DOM03) grid spacing and for the RADOLAN composite.

\begin{tabular}{lrrrr}
\hline Ratio (number; amount) (\%) & DOM01 & DOM02 & DOM03 & RADOLAN \\
\hline Solitary tracks & $34.0 ; 9.4$ & $32.7 ; 7.1$ & $32.3 ; 4.2$ & $31.5 ; 6.7$ \\
Involving only merging & $25.4 ; 36.7$ & $26.3 ; 27.7$ & $26.7 ; 28.2$ & $26.5 ; 26.7$ \\
Involving only splitting & $28.5 ; 24.1$ & $28.7 ; 25.4$ & $27.7 ; 20.4$ & $27.5 ; 34.2$ \\
Both merging and splitting & $12.1 ; 29.7$ & $12.3 ; 39.8$ & $13.3 ; 47.2$ & $14.5 ; 32.4$ \\
\hline
\end{tabular}

ther, Fig. $6 \mathrm{~b}$ confirms that RADOLAN track maximum sizes are best matched with the coarse $625 \mathrm{~m}$ domain, while sizes are smaller at higher resolutions. The spread of the maximum size distribution is relatively narrow compared to intensities and is similar for all resolutions and for the RADOLAN data. Not surprisingly, the resulting total amount of precipitation produced by the tracks (Fig. 6c) strongly increases with track duration. For tracks longer than $1 \mathrm{~h}$, the spread of the inner quartiles between model data and RADOLAN matches best for the $625 \mathrm{~m}$ domain, while the median matches better with the finer nests, although they show a clearly smaller spread.

To briefly summarize this section, both the convective organization indices and the rain cell tracking show that for the higher-resolution nests there is a stronger tendency of convection to organize, which generally provides a better match with RADOLAN data. Further, convective precipitation increases more rapidly at the onset of convection at $625 \mathrm{~m}$ grid spacing, compared to the finer resolutions and the RADOLAN data. This can be seen in both the diurnal cycle of mean precipitation and the life cycle composites of the solitary tracks. Although three model resolutions are insufficient to clearly identify bulk convergence and structural convergence, these results show an improved simulation of convection at the $100 \mathrm{~m}$ scale with ICON-LEM. 

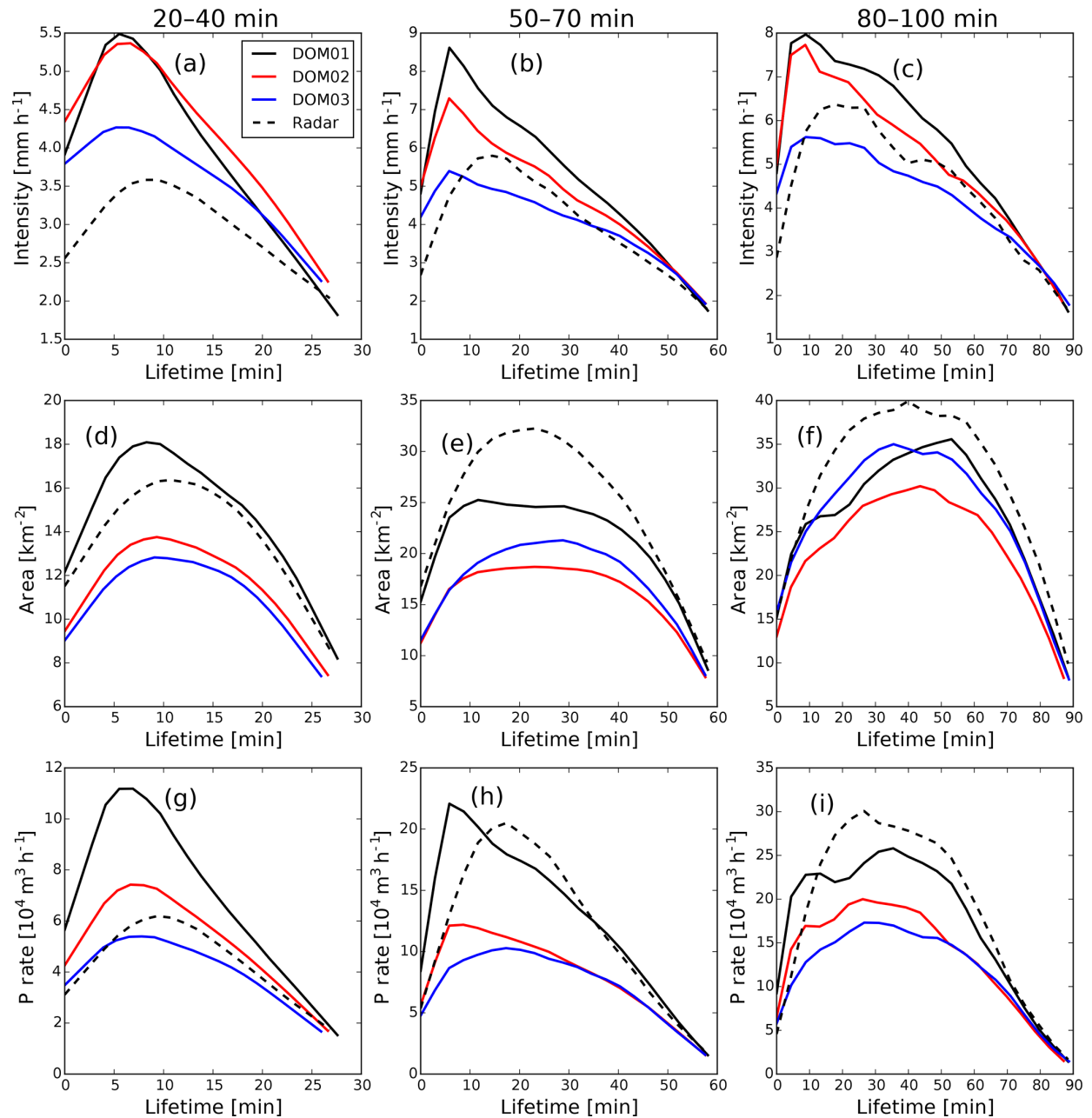

Figure 5. Life cycles of track composites (including the days 29 May, 3 June, and 6 June) for solitary tracks of different track duration for model results in three domains with $625 \mathrm{~m}$ (DOM01), $312 \mathrm{~m}$ (DOM02), and $156 \mathrm{~m}$ (DOM03) grid spacings and for radar results. Curves show mean track life cycles of area-mean precipitation intensity $(\mathbf{a}-\mathbf{c})$, area of precipitation objects $(\mathbf{d}-\mathbf{f})$, and rate of total precipitation (that is the areal integral of local precipitation intensity over the object extent) (g-i), conditioned on tracks with durations between 20 and $40 \mathrm{~min}$ (a, d, g), between 50 and $70 \mathrm{~min}(\mathbf{b}, \mathbf{e}, \mathbf{h})$, and between 80 and $100 \mathrm{~min}(\mathbf{c}, \mathbf{f}, \mathbf{i})$.

\section{Analysis of the continuous $36 \mathrm{~d}$ period with $625 \mathrm{~m}$ grid spacing}

\subsection{Mean diurnal cycles}

In the previous section we argued that the ICON-LEM setup with $625 \mathrm{~m}$ grid spacing is sufficient to reasonably simulate typical convective summer days over Germany, although there may still be room for added value at even higher resolutions. We now discuss the continuous simulation period from 26 May until 20 June 2016, simulated with $625 \mathrm{~m}$ grid spacing. The simulated domain mean precipitation with the RADOLAN data for the full period is shown in Fig. 7. On some of the days we see an underestimation of simulated rainfall compared to RADOLAN, like on 30 May, 12 June, and 16 June and in the $3 \mathrm{~d}$ period between 23 and 25 June. However, there are few days where the precipitation intensity is slightly overestimated, like on 19 and 26 June. Another mismatch between model and radar data is that daily peak intensities tend to be reached $1-3 \mathrm{~h}$ earlier in the model simulation compared to RADOLAN. This is particularly visible in the $6 \mathrm{~d}$ period of 3-8 June. This feature can be explained by the observation discussed in the Sect. 3, where we argued that convection is triggered too fast in the $625 \mathrm{~m}$ LES. We note that in addition to these systematic differences, some of the differences between model and radar data could also be traced back to the uncertainty in boundary conditions from the COSMO forecast data.

To confirm that the simulated $36 \mathrm{~d}$ convective period is long enough to show the intensification of convection with higher temperatures as discussed in the introduction and that it is also simulated with ICON-LEM and $625 \mathrm{~m}$ grid spacing, we perform a separate analysis for selected cool and 

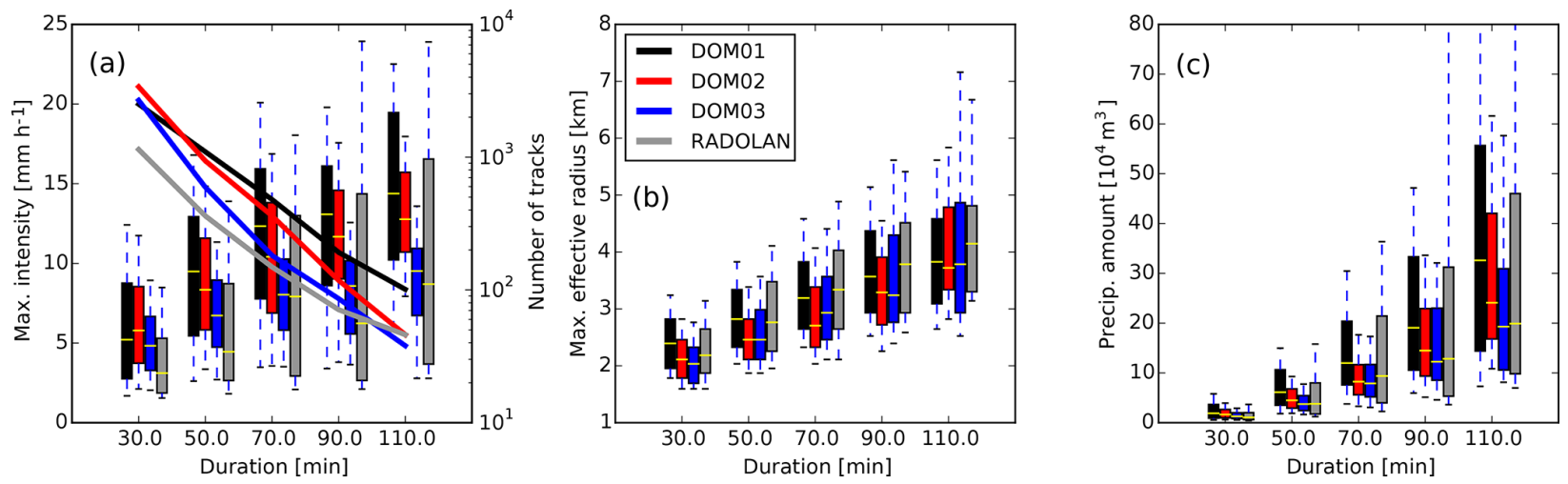

Figure 6. Box-and-whisker plots showing the statistics of solitary tracks, including the days 29 May, 3 June, and 6 June in all three domains with $625 \mathrm{~m}$ (DOM01), $312 \mathrm{~m}$ (DOM02), and $156 \mathrm{~m}$ (DOM03) grid spacing and for the radar data. Values of track maximum intensity (a), track maximum effective radius (b), and total precipitation amount produced by the individual tracks (c) are conditioned on track duration ranging between 20 and $120 \mathrm{~min}$, in five bins of $20 \mathrm{~min}$ width. Boxes indicate the 25th and 75th percentiles, and the median (yellow bar), whiskers indicate the 10th and 90th percentiles. The number of tracks in each bin is indicated by the solid lines in panel (a) (note the logarithmic axis on the right).

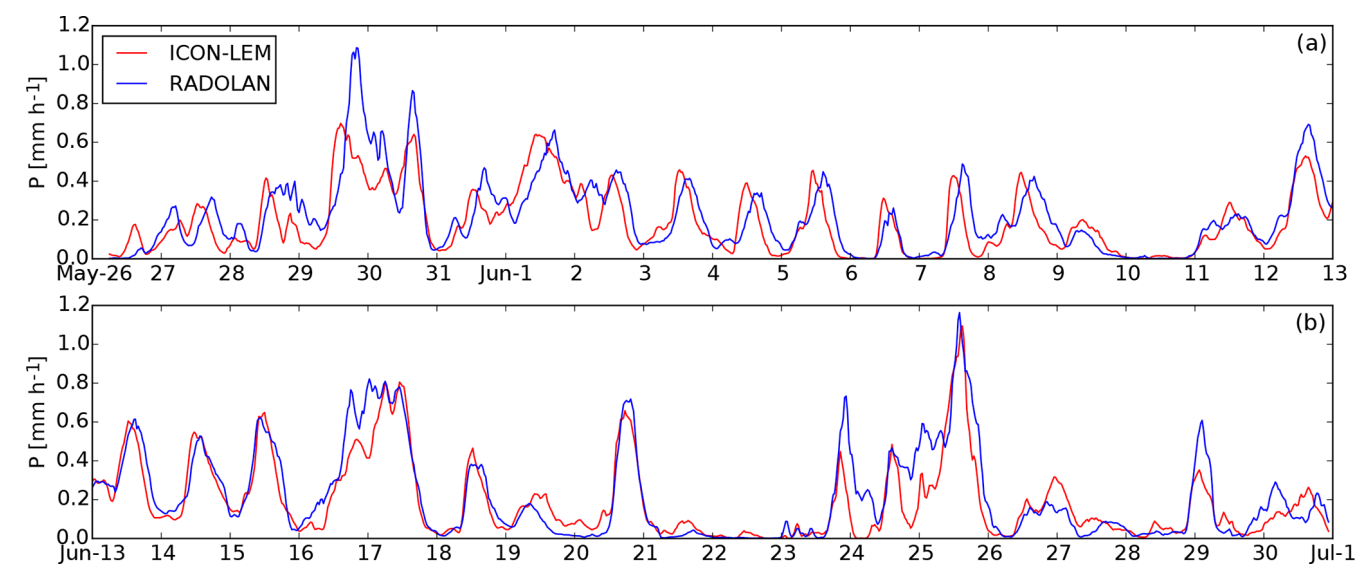

Figure 7. Time series of the mean precipitation intensity $P$ for the $625 \mathrm{~m}$ grid spacing ICON-LEM simulation, and the RADOLAN-derived precipitation intensity, for the full $36 \mathrm{~d}$ period from 26 May until 30 June 2016. Note that the time series was broken into the upper and the lower panels. Averaging was carried out over all grid boxes where radar data are available.

warm days. We calculate the domain mean temperature from the original COSMO-DE forcing data, and we average over the time between 08:00 and 20:00 UTC when daytime convection is expected. We hereby use the original COSMO$\mathrm{DE}$ analysis data that provided the forcing, as we expect them to be closer to the actual temperatures than the temperatures simulated by ICON-LEM. We classify days below $16^{\circ} \mathrm{C}$ daytime mean $2 \mathrm{~m}$ temperature as cool and between 19 and $21^{\circ} \mathrm{C}$ as warm. The 2 exceptionally warm days 23 and 24 June with mean temperatures of 26.0 and $24.1^{\circ} \mathrm{C}$, respectively, are not included in the ensemble of warm days. Further, 22 June was removed from the classification due to the very low precipitation amount (otherwise it should have been classified as a warm day). An overview of the classified days can be seen in Table A1. In total, out of the $36 \mathrm{~d}$ of the simulation, we classify $6 \mathrm{~d}$ as cool and $6 \mathrm{~d}$ as warm.
Mean diurnal cycles of several domain-averaged quantities, including all $36 \mathrm{~d}$, and conditioned on cool and warm days are shown in Fig. 8. As already mentioned, the peak in mean precipitation (Fig. 8a) appears earlier in the model than in the RADOLAN data, and it is higher for the cold days than for the total mean of all days. For warm days, the peak is also slightly larger than for the total mean, although there is less precipitation in the afternoon hours after 15:00 UTC. The simulation period is too short to significantly state if there is any direct correlation between the total amount of precipitation and the daily mean temperature. However, there is clear temperature dependence of the 99th percentile of precipitation intensity (Fig. 8b): consistent with the CC argument mentioned in the introduction, there is less (more) water vapor available in the atmosphere on cool (warm) days than on average (Fig. 8c), associated with 

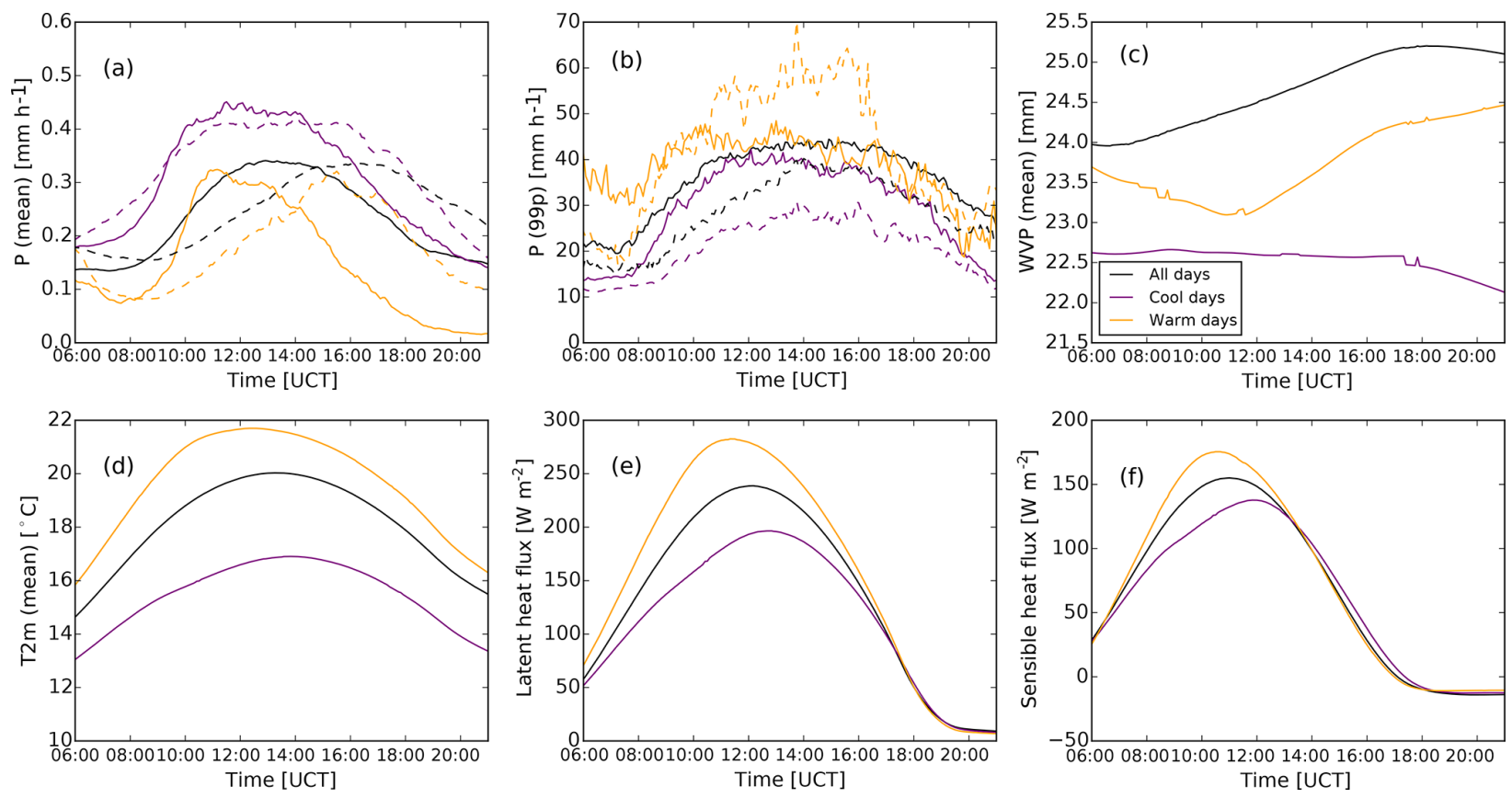

Figure 8. Diurnal cycles of mean precipitation intensity (a), 99th percentile of precipitation intensity (b), water vapor path (c), air temperature at $2 \mathrm{~m}$ (d), surface latent heat flux (e), and surface sensible heat flux (f), for all days, cold days, and warm days of the $36 \mathrm{~d}$ simulation with $625 \mathrm{~m}$ grid spacing. In panels (a) and (b), solid lines show simulation data, and dashed lines show RADOLAN data. Averaging was carried out over all grid boxes where radar data are available.

lower (higher) extreme rainfall intensities. However, the differences in the 99th percentile of precipitation are more pronounced in the RADOLAN data, suggesting that the sensitivity of heavy rainfall to temperature is underestimated by the model. Further, we see that cool (warm) days are associated with lower (higher) surface fluxes (Fig. 8d-f). As a sensitivity test, we randomly chose 3 out of the 6 warm days and 3 out of the 6 cool days, and we reproduced the plot in Fig. 8b with these days (not shown). Repeating this procedure four times confirmed that peak intensities of the 99th percentiles are stronger (weaker) for warm (cool) days in both radar and model data and that the difference between warm and cool days is weaker in the model than in the radar data.

\subsection{Diurnal cycles of convective organization indices}

We calculate mean diurnal cycles of the convective organization indices SCAI, COP, $I_{\text {org }}$, and $I_{\text {shape }}$, for model and RADOLAN data of all $36 \mathrm{~d}$ and conditioned on cool and warm days (Fig. 9). SCAI, COP, and $I_{\text {org }}$ indicate more organization in the morning and evening, when the objects also present a more elliptical shape (Fig. 9d). During the afternoon, when the convective activity is more intense, there is a decrease in the degree of organization, with the shape of the objects tending towards a more circular one. ICON reproduces the diurnal cycle of $I_{\text {org }}$ very well (Fig. 9c). Although the variability of SCAI, COP, and $I_{\text {shape }}$ is captured by the model at $625 \mathrm{~m}$ grid spacing, it underestimates the degree of organization revealed by RADOLAN (Fig. 9a-b) and produces more rounded objects than the radar observations (Fig. 9d), especially in the afternoon, as was discussed in Sect. 3.2.

For the 6 cool days, SCAI is in general larger, while COP is lower than the corresponding indices for the $36 \mathrm{~d}$ period (Fig. 9e, f), indicating the presence of more numerous and smaller objects. Although the degree of organization of these objects is weaker than for the full period (Fig. 9e-g), the variability in the shape (Fig. 9h) is similar to that in the larger period. In contrast to the cool days, during the 6 warm days, SCAI and COP show a diurnal cycle similar to that of the $36 \mathrm{~d}$ period (Fig. 9i, j), revealing the presence of fewer and larger objects, which favors organization. $I_{\text {org }}$ also indicates a stronger degree of organization (Fig. 9k) in comparison with the cool days. Although $I_{\text {shape }}$ is noisier on warm days, it also follows a behavior similar (Fig. 91) to that seen during the longer period.

Overall, although the indices hint at an underrepresentation of convective organization and more compact objects in the $625 \mathrm{~m} \mathrm{LES}$, the radar and model agree that organization is stronger on warmer days. However, there is a less clear signal for the warm days compared to the average than for the cool days. 

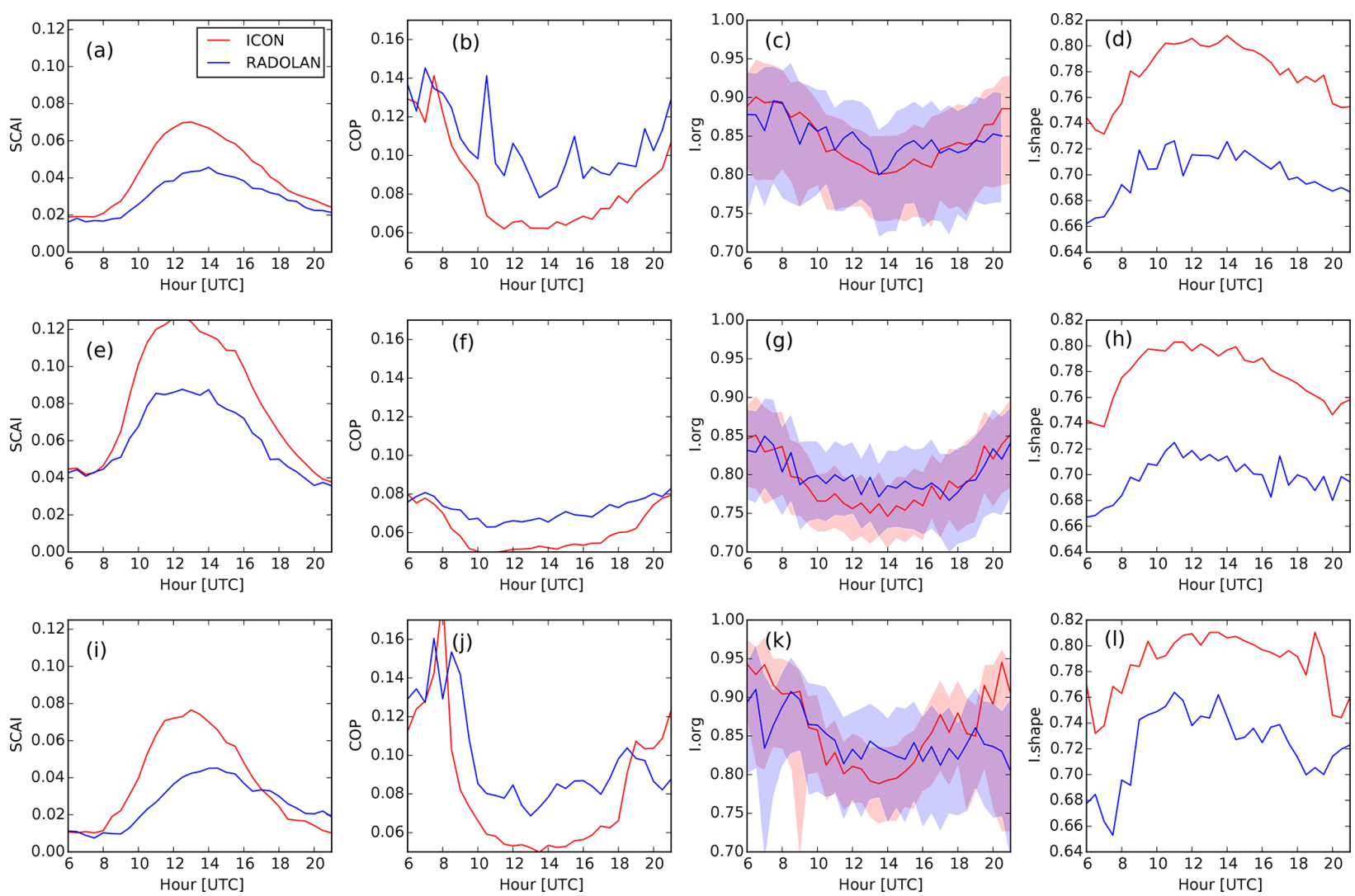

Figure 9. Mean diurnal cycles of the convective organization indices SCAI (a, e, i), COP (b, f, j), $I_{\text {org }}(\mathbf{c}, \mathbf{g}$, $\mathbf{k}$; color shading shows the range between percentiles 2.5 and 97.5 as described in Sect. 2.4), and $I_{\text {shape }}(\mathbf{d}, \mathbf{h}, \mathbf{l})$, for all days (a-d), for cool days (e-h), and for warm days (i-l), for the model simulation with $625 \mathrm{~m}$ grid spacing and for RADOLAN. Averaging was carried out over all grid boxes where radar data are available.

Table 2. Ratio of the number of tracks of given track types (solitary, tracks that involve only merging, tracks that involve only splitting and tracks involving both merging and splitting), and the total amount of rainfall that they contribute, relative to the total number and rainfall amount of all tracks. Tracks that touch the domain boundaries are removed from the analysis. Fractions (in percent), including all 36 model days, and conditioned on only the cold and the warm days, as defined in Table A1, are given for both the model simulation (M) and the RADOLAN composite (R).

\begin{tabular}{lrrrrrr}
\hline Ratio (number; amount) $(\%)$ & All days $(\mathrm{M})$ & Cool days $(\mathrm{M})$ & Warm days $(\mathrm{M})$ & All days $(\mathrm{R})$ & Cool days $(\mathrm{R})$ & Warm days $(\mathrm{R})$ \\
\hline Solitary tracks & $38.8 ; 12.1$ & $35.5 ; 11.9$ & $39.1 ; 13.6$ & $29.8 ; 5.1$ & $26.5 ; 4.1$ & $35.7 ; 8.4$ \\
Involving only merging & $23.1 ; 27.0$ & $23.8 ; 27.4$ & $24.1 ; 28.7$ & $27.8 ; 25.1$ & $28.9 ; 25.1$ & $26.9 ; 28.5$ \\
Involving only splitting & $27.1 ; 26.5$ & $28.6 ; 28.3$ & $27.1 ; 25.6$ & $27.6 ; 24.2$ & $28.7 ; 23.1$ & $25.2 ; 27.8$ \\
Both merging and splitting & $11.0 ; 34.4$ & $12.1 ; 32.4$ & $9.7 ; 32.1$ & $14.8 ; 25.6$ & $15.8 ; 47.7$ & $12.1 ; 35.3$ \\
\hline
\end{tabular}

\subsection{Track statistics}

We have shown in Sect. 3.3 that in addition to the four convective organization indices, the rain cell tracking result provides information on the degree of organization in the three different model resolutions. In this section we apply the rain cell tracking in a similar way on the $36 \mathrm{~d}$ continuous simulation with $625 \mathrm{~m}$ grid spacing with a separate analysis for the 6 cool days and 6 warm days. Table 2 shows that there is a consistent trend in the ratio of both the number and the total precipitation produced by solitary tracks and that this trend is the same for model and RADOLAN data: there is a smaller fraction of solitary tracks on the cold days and a larger one on the warm days, compared to the full simulation period. Likewise, the solitary tracks contribute to a fraction of total rainfall that is smaller on cold days but larger on warm days. This trend is weaker in the model than in the radar data. At first glance, this result seems to contradict our analysis of the 3 three-domain days, where we argued that a larger contribution of solitary tracks corresponds to a weaker degree of 
organization: instead, the organization indices in Fig. 9 show weaker organization on the cold days, although the contribution of solitary tracks is smaller, meaning that a larger fraction of tracks are subject to merging or splitting events. However, it should be kept in mind that there was also more total precipitation in the analysis domain on the cool days compared to the total simulation period (Fig. 7), which is also reflected by the total number of tracks: while there are on average 21533 solitary tracks per day for the full model period, the number of solitary tracks per day for the cold days was 33367 and therefore in total larger, while for the warm days there was a smaller number of only 20010 solitary tracks per day. For the RADOLAN data, these numbers were 8882 (all days), 17288 (cool days), and 9024 (warm days). Therefore, model and RADOLAN data agree on a larger total number of solitary tracks for the 6 cool days, in consistency with the hypothesis that a weaker organization on the cool days is associated with a larger number of non-interacting rain cells. That the solitary track ratio with respect to the total number of all tracks is slightly smaller on the cool days could be due to the fact that the larger number of precipitation objects (as indicated by the SCAI and COP indices) makes it more likely that neighboring objects interact with each other. This phenomenon was observed in the idealized LES study by Moseley et al. (2019) where model simulations with more convective rainfall and a larger number of rain cells showed a larger contribution of interacting rain cells to the total precipitation. We note that due to the large differences in the total number of tracks between warm and cool days, the tracking statistics are more difficult to interpret here, compared to the more robust differences in track statistics between resolutions presented in Sect. 3.3.

The box-and-whisker plots in Fig. 10 show the statistics of maximum track intensities, maximum cell radii, and total precipitation amount of the solitary tracks. The solid lines in Fig. 10a-c show that the abovementioned larger number of solitary tracks per day of the cold days (Fig. 10b) is distributed over all track durations. Compared to the total ensemble of all $36 \mathrm{~d}$, a smaller (larger) fraction of solitary tracks reach higher maximum intensities on cool (warm) days, and in consistency with the 99th percentile of rain intensities shown in Fig. $7 \mathrm{~b}$ there is a weaker temperature sensitivity seen for the model data compared to RADOLAN. This intensification of the solitary tracks with temperature, especially for the tracks with a lifetime longer than $1 \mathrm{~h}$, can be seen even more clearly in the total amount of precipitation produced by the tracks (Fig. 10g-i). A dependence of the cell sizes reached by solitary tracks in temperature is less clear (Fig. 10d-f).

To briefly summarize the tracking result in this paragraph, we find that solitary tracks of comparable duration can reach higher precipitation amounts on warm days compared to cool days. This shows an intensification of solitary convective rain tracks with temperature. However, this intensification is found to be weaker for the model data compared to
RADOLAN. Furthermore, a larger number of solitary tracks on cool days in both model and RADOLAN data is consistent with a weaker degree of convective organization.

\section{Discussion}

We have evaluated the impact of horizontal resolution on explicitly simulated convective precipitation, and we analyzed the sensitivity of convective organization to daily mean $2 \mathrm{~m}$ air temperature on the $36 \mathrm{~d}$ continuous simulation with $625 \mathrm{~m}$ grid spacing. The impact of horizontal resolution is significant. Our study indicates that compared to the RADOLAN data, the diurnal cycles, life cycles, and degree of convective organization are simulated better at the innermost nest with $156 \mathrm{~m}$ horizontal grid spacing. This is in agreement with previous studies which argued that for a sufficient resolution of the processes within deep convective updrafts, models with grid spacing of the order of ca. $100 \mathrm{~m}$ are required (Petch et al., 2002; Bryan et al., 2003) and that there is neither bulk convergence nor structural convergence at coarser resolutions (Panosetti et al., 2019). At $625 \mathrm{~m}$ and to a smaller degree at $312 \mathrm{~m}$ grid spacing, convection tends to set in too rapidly, and many isolated deep convective cells are scattered over the domain. In contrast, at $156 \mathrm{~m}$, we find a smoother onset of convective updrafts with lower peak intensities and a stronger degree of organization that in general shows a better match with the radar data. In addition, the tracking analysis revealed that the stronger organization of the more highly resolved simulations is accompanied by an increased tendency of convection to form larger clusters: the $156 \mathrm{~m}$ simulation shows a lower number of isolated rain cells, and their contribution to total rainfall is lower. Vice versa, the total contribution of the tracks that undergo merging and splitting is clearly higher for the more highly resolved simulations. Petch et al. (2002) argue that at coarser resolutions the models fail to compensate for the lack of resolved transport out of the subcloud layer, leading to a delayed spin-up of convection relative to that obtained in the better-resolved simulations. This delay in the spin-up might then lead to the too explosive convective initiation that we find in our analysis. We speculate that this could also be the reason for the suppressed organization of the $625 \mathrm{~m}$ simulation compared to radar: as soon as a convection cell is initiated, it is already fully developed and therefore does not have enough time to interact with neighboring cells within its lifetime. However, this is a hypothesis that should be tested in a future study. Such a study should investigate the processes that happen within merging cells in more detail.

An improved subgrid scheme might lead to more realistic results and a decreased sensitivity to resolution, while the Smagorinsky subgrid scheme used in our model seems to not be the optimal choice at $625 \mathrm{~m}$ grid spacing, as some of the larger boundary-layer eddies are likely unresolved. We also note that the microphysics scheme might have significant im- 

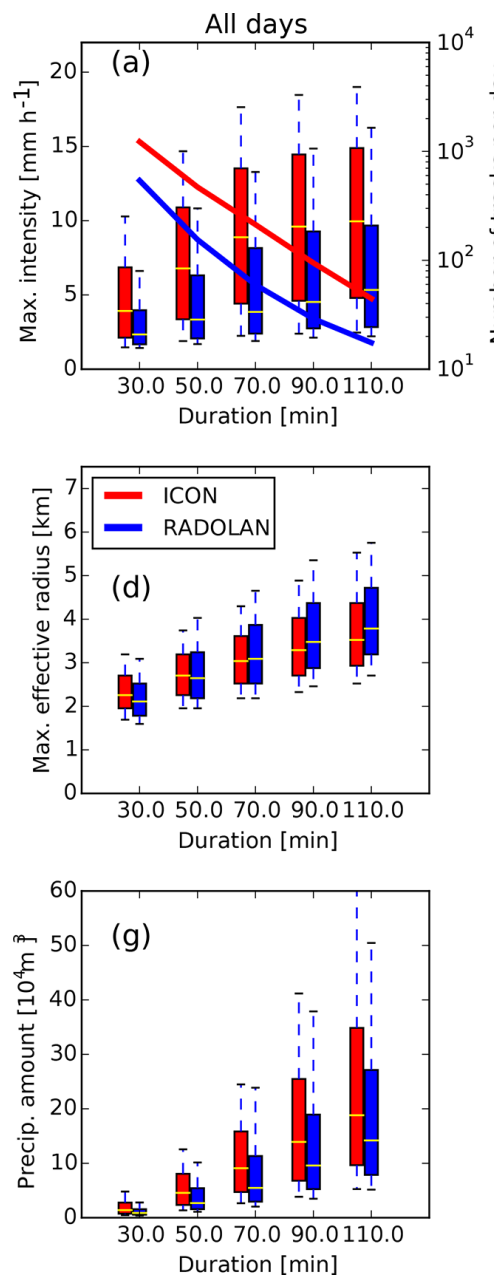
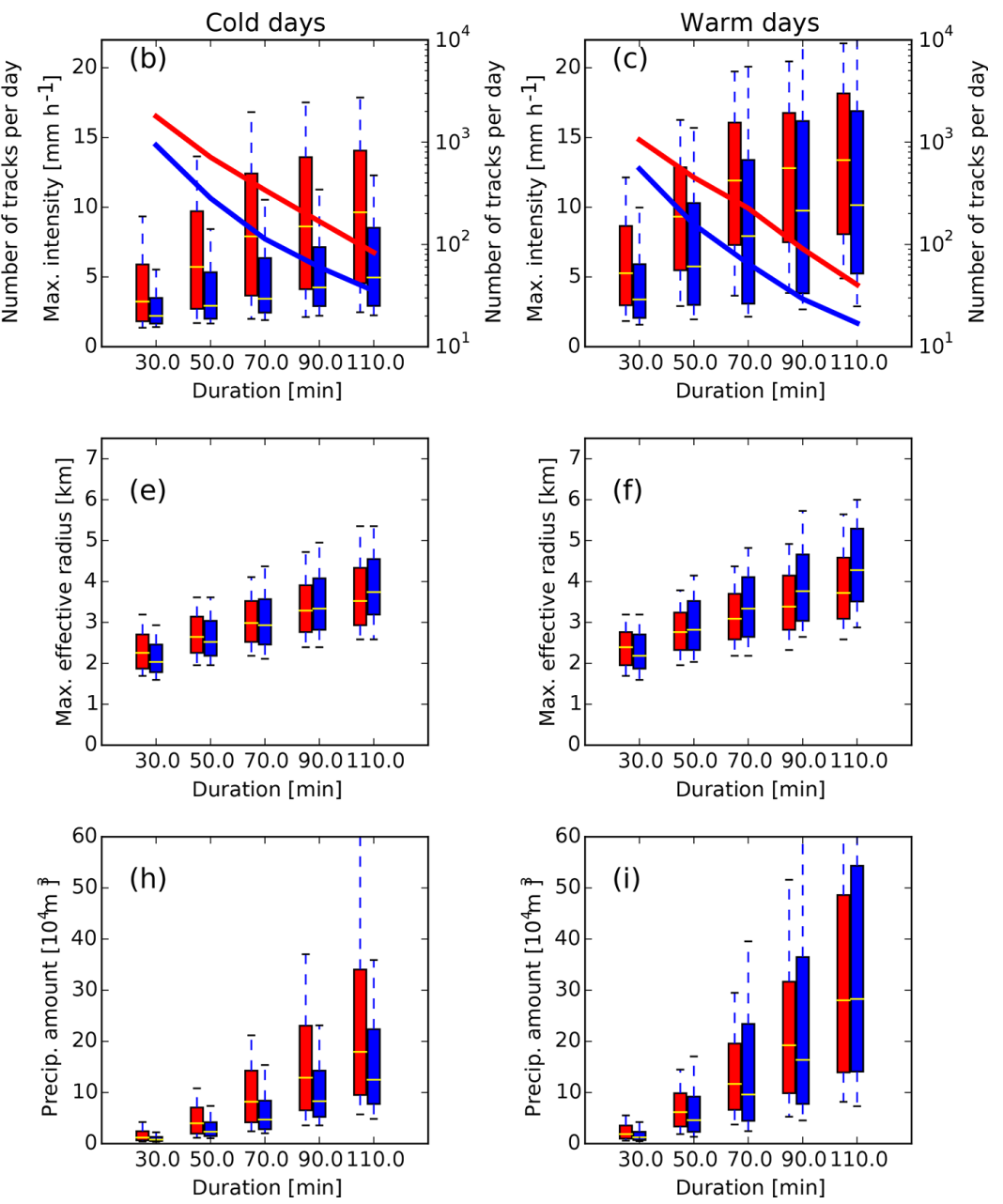

Figure 10. Box-and-whisker plots showing the statistics of solitary tracks for the whole $36 \mathrm{~d}$ period, for all (a, d, $\mathbf{g})$, cool (b, e, h), and warm $(\mathbf{c}, \mathbf{f}, \mathbf{l})$ days. Values of track maximum intensity $(\mathbf{a}-\mathbf{c})$ and track maximum effective radius $(\mathbf{d}-\mathbf{f})$ and total amount of precipitation produced by the individual tracks (g-l) are conditioned on track duration ranging between 20 and 120 min, in five bins of 20 min width. Boxes indicate the 25th and 75th percentiles and the median (red bar); whiskers indicate the 10th and 90th percentiles. The number of tracks in each bin is indicated by the solid lines in panels (a)-(d) (note the logarithmic axis on the right).

pacts on organized convection. An analysis of the impact of different physical parametrizations on the simulated convection is not covered here, and we encourage future studies in this direction.

Similar to Pscheidt et al. (2019), we find in general a too large number of small clouds as indicated by the rain cell size distribution and also by the SCAI and COP indices in the model simulations, but in contrast to their findings we see a tendency towards fewer and larger objects at high resolution, which we find more realistic as evaluated against the RADOLAN data. Further, similar to our study, Pscheidt et al. (2019) find that objects are more elliptic at higher resolution as indicated by the $I_{\text {shape }}$ index. However, they find this to be less realistic compared to RADOLAN and satellite data, while in 2 of the $3 \mathrm{~d}$ that we analyzed $I_{\text {shape }}$ at the $156 \mathrm{~m}$ nest matches better with RADOLAN. Although Pscheidt et al. (2019) use the same model at the same resolutions, and partly the same observational data as in our study, they have analyzed different model days. Thus, the reason for the discrepancies might be that differences among different model resolutions depend on synoptic situations, which indicates that a larger sample of model days is needed to confirm the hypothesis that convective organization is better simulated at $156 \mathrm{~m}$ grid spacing. However, our hypothesis is also supported by the tracking result, which shows that there are fewer solitary tracks (which - in turn - means more interaction between tracks) at higher resolutions, which provides a better match to the RADOLAN data. Pscheidt et al. (2019) recommend that COP and SCAI can be replaced by object sizes and object number, respectively, since they are mainly influenced by these two quantities. However, supplementary information on the degree of organization is provided by $I_{\text {shape }}$ and $I_{\text {org }}$, in particular since the latter is able to distinguish between three possible categories: organized, regular, and ran- 
dom. Our study confirms this hypothesis, with the addition that tracking objects in time can give valuable information on the tendency of convection to form clusters. Another possible improvement could be new indices that take into account both ends of the size distribution function separately: Neggers et al. (2019) have shown that spatial organization affects both ends of the cloud size PDF, but in different ways: while the number of large clouds increases, there is an enhanced variability in the number of small clouds, especially shallow cumulus clouds below the $1 \mathrm{~km}$ scale. However, in our study, we are mainly concerned with deep precipitating convection where such small cloud sizes are neglected.

Consistent with theory, our analysis of the continuous $36 \mathrm{~d}$ period with $625 \mathrm{~m}$ grid spacing shows that convection becomes more intense with higher near-surface temperatures. A separate analysis of $6 \mathrm{cool}$ (below $16^{\circ} \mathrm{C}$ ) and 6 warm days (19-21 ${ }^{\circ} \mathrm{C}$ ) shows a consistent increase with temperature in the 99th percentile of precipitation intensity, as well as in the total amount of precipitation generated by solitary tracks. This finding is encouraging, since it confirms that the increase in extreme precipitation with temperature can be represented with CRMs at the kilometer scale. However, in our simulation period the simulated increase from cool to warm days is smaller in magnitude than in the RADOLAN data. In addition to heavy precipitation intensities, we also find a temperature sensitivity of the convective precipitation indices: in particular, they show a weaker degree of organization for the cool days in both model and RADOLAN data. Although this is consistent with a larger number of solitary tracks on the cool days, the fraction of solitary tracks is smaller on the cool days. This is probably due to the fact that although the degree of organization might be weaker, there was more total precipitation on the cool days in our simulation period, making an interaction of precipitation objects more likely since they are on average closer together. The large differences in the total number of tracks between warm, cool, and all days in the analysis of the temperature sensitivity makes the interpretation of the tracking result more difficult, compared to the resolution analysis. A deeper investigation of the interaction between events is left to a future study, and the idealized study by Moseley et al. (2016) suggests that interaction between cells might well be intensified with higher temperatures. Our study also cannot answer the question of whether higher resolution will lead to an improved simulation of the sensitivity of heavy rainfall and convective organization to temperature, as too few model days for all three nests are available. Given that the magnitude of the intensification of heavy rainfall with temperature has both a thermodynamic (based on the CC argument) and a dynamic aspect, and that thermodynamic processes can be expected to be rather independent of resolution, we can assume that it is mainly an insufficient representation of the dynamics within the convection cells that causes an underestimated intensification at $625 \mathrm{~m}$ grid spacing. Although, in contrast to our results, Ban et al. (2014) do not report an underestimated tempera- ture sensitivity of heavy rainfall in Switzerland with a $2.2 \mathrm{~km}$ model, the strong orography in their study region is absent in the largest part of our simulation domain, such that a direct comparison to our study may be difficult.

In addition to these findings, we have shown that the iterative rain cell tracking (IRT) method is not only a useful tool to study the life cycles of isolated convective rain events (that is, solitary tracks), but it is also able to provide information on the convective organization in the model simulations and observational data. In general, a smaller total contribution of isolated cells to the total rainfall indicates that the tendency of convection to interact and form clusters is larger, since it means that a larger fraction of tracks experiences merging and splitting. Therefore, our tracking result is consistent with the convective organization indices. However, as also stated by Rasp et al. (2018), these indices describe only the spatial structure of the convection, but they neglect the temporal structures of convective memory, which is an import aspect for parametrizations. Therefore, there is the need for new types of indices that also involve information on the temporal evolution of convective organization. A further development of our tracking method may fill this gap, as it includes the time evolution of convection cells and therefore has the potential to provide a more comprehensive description of the processes that happen when repeated merging of individual convection cells leads to large clusters, such as mesoscale convective systems, squall lines, and tropical cyclones.

Finally, we mention another important aspect that we have not addressed in the present study, but which however has been shown to have an important impact on convective organization, namely cold pools: when cold pool gust fronts collide, they sometimes trigger another convective precipitation cell, leading to a complex feedback between the convective rain cells and the cold pools that they generate (Haerter et al., 2019). Cold pools are clearly visible in our model data, and an analysis of their role in triggering new convection cells will be published in a separate paper (Hirt et al., 2020).

\section{Conclusions}

Based on a $36 \mathrm{~d}$ continuous simulation for May and June 2016, we have shown that ICON in a limited-area setup over Germany with a grid spacing of $625 \mathrm{~m}$ is able to simulate an intensification of isolated convective rain cells with temperature. However, the magnitude of the simulated intensification is smaller than shown by the RADOLAN radar composite. Further, we find a weaker degree of organization in particular on cooler days, which is reflected by the convective organization indices, but also by a larger number of non-interaction (solitary) rain cell tracks.

An analysis of the $3 d$ that are available for all three nests showed that the convective organization pattern is best simulated at the highest resolution with $156 \mathrm{~m}$ grid spacing. At the coarsest nest with $625 \mathrm{~m}$ grid spacing, we find that con- 
vective events are too strong at the beginning of their life cycles, that they are more weakly organized, and that they show a weaker tendency to merge and form clusters. This indicates that not all processes in the convective updrafts are optimally resolved at this resolution. Overall, our evaluation of the three model resolutions suggests that an increase in model resolution toward the $100 \mathrm{~m}$ scale has the potential to provide a more realistic simulation of convection.

Based on our finding that stronger convective organization is associated with a smaller number of non-interacting tracks and more merging and splitting events between objects, we propose the development of new convective organization indices that are capable of monitoring not only the spatial but also the temporal evolution of the convective clustering process. Such indices could be based on existing tracking algorithms such as the IRT method that we applied within this study. 


\section{Appendix A: Overview of simulated days}

Table A1. Mean $2 \mathrm{~m}$ temperature $T$ and $10 \mathrm{~m}$ wind speed $v$ for each day, averaged over COSMO analysis data between 08:00 and 20:00 UTC; daily precipitation sums $P_{\mathrm{M}}$ from model output; and $P_{\mathrm{R}}$ from RADOLAN. In the temperature column, footnotes show days classified as $\operatorname{cool}\left({ }^{\mathrm{c}}\right)$, warm $\left({ }^{\mathrm{w}}\right)$, and very warm $\left({ }^{\mathrm{v}}\right)$. The days marked with ${ }^{\mathrm{a}}$ are simulated for three domains.

\begin{tabular}{|c|c|c|c|}
\hline Month-day & $T\left({ }^{\circ} \mathrm{C}\right)$ & $P_{\mathrm{M}}(\mathrm{mm})$ & $P_{\mathrm{R}}(\mathrm{mm})$ \\
\hline $05-26$ & 16.9 & 1.58 & 0.80 \\
\hline $05-27$ & 17.7 & 3.50 & 3.88 \\
\hline $05-28$ & 18.9 & 3.46 & 4.71 \\
\hline $05-29^{a}$ & 18.2 & 8.32 & 11.11 \\
\hline $05-30$ & 17.4 & 9.11 & 10.98 \\
\hline $05-31$ & 17.5 & 3.93 & 5.06 \\
\hline 06-01 & 17.2 & 10.48 & 9.35 \\
\hline 06-02 & 17.1 & 5.09 & 7.43 \\
\hline $06-03^{a}$ & 18.1 & 4.7 & 4.63 \\
\hline 06-04 & $19.5^{\mathrm{W}}$ & 3.07 & 3.59 \\
\hline 06-05 & $20.0^{\mathrm{w}}$ & 3.28 & 4.55 \\
\hline $06-06^{\mathrm{a}}$ & $20.5^{\mathrm{w}}$ & 1.72 & 1.49 \\
\hline 06-07 & $20.7^{\mathrm{w}}$ & 2.28 & 3.47 \\
\hline 06-08 & 17.8 & 3.67 & 5.21 \\
\hline 06-09 & 16.5 & 1.72 & 1.56 \\
\hline $06-10$ & 17.3 & 0.14 & 0.12 \\
\hline $06-11$ & 16.4 & 2.96 & 3.68 \\
\hline $06-12$ & $15.9^{\mathrm{c}}$ & 7.01 & 8.96 \\
\hline $06-13$ & $15.7^{\mathrm{c}}$ & 7.36 & 8.00 \\
\hline $06-14$ & $15.9^{\mathrm{c}}$ & 6.07 & 6.71 \\
\hline $06-15$ & $15.8^{\mathrm{c}}$ & 6.19 & 7.04 \\
\hline $06-16$ & 17.0 & 5.19 & 7.42 \\
\hline $06-17$ & $15.4^{\mathrm{c}}$ & 11.12 & 12.03 \\
\hline $06-18$ & 16.2 & 3.31 & 3.68 \\
\hline 06-19 & $15.3^{\mathrm{c}}$ & 2.31 & 1.71 \\
\hline $06-20$ & 17.2 & 7.50 & 6.63 \\
\hline $06-21$ & 18.4 & 1.20 & 0.70 \\
\hline $06-22$ & 22.0 & 0.30 & 0.11 \\
\hline $06-23$ & $26.0^{\mathrm{V}}$ & 2.77 & 4.07 \\
\hline $06-24$ & $24.1^{\mathrm{V}}$ & 3.12 & 6.93 \\
\hline $06-25$ & $19.6^{\mathrm{W}}$ & 11.11 & 15.09 \\
\hline $06-26$ & 17.2 & 2.11 & 2.02 \\
\hline $06-27$ & 17.3 & 2.35 & 1.67 \\
\hline $06-28$ & 18.5 & 1.50 & 1.33 \\
\hline $06-29$ & $19.3^{\mathrm{W}}$ & 2.82 & 4.14 \\
\hline $06-30$ & 18.6 & 2.89 & 3.55 \\
\hline
\end{tabular}


Code and data availability. Primary data and scripts used in the analysis that may be useful in reproducing the author's work are archived by the Max Planck Institute for Meteorology and can be obtained via the institutional repository http://hdl. handle.net/21.11116/0000-0004-8662-6 (Moseley and Pscheidt, 2020). The rain cell tracking code is available via https://github. com/christophermoseley/iterative_raincell_tracking (Moseley and Haerter, 2020).

Author contributions. RH, GC, and CM designed and performed the model simulations, CM performed the tracking analysis, and IP calculated the convective organization indices. CM conceived the original idea and coordinated the analysis. All authors contributed to the manuscript.

Competing interests. The authors declare that they have no conflict of interest.

Acknowledgements. We thank the German Climate Computing Center (DKRZ) for providing computing resources and assistance with the performance of the ICON simulations. The German Weather Service (DWD) is acknowledged for providing the RADOLAN radar composite. We thank Sophia Schäfer, Cathy Hohenegger, and the two anonymous referees for reviewing the manuscript and providing suggestions for improvement. We acknowledge funding through the German Federal Ministry of Education and Research for the project " $\mathrm{HD}(\mathrm{CP})^{2}-$ High definition clouds and precipitation for advancing climate prediction" within the framework program "Research for Sustainable Development (FONA)", under 01LK1506F, 01LK1501B, 01LK1507B, and 01LK1507A.

Financial support. This research has been supported by the German Federal Ministry of Education and Research (BMBF) (grant nos. 01LK1506F, 01LK1501B, 01LK1507B, and 01LK1507A.).

The article processing charges for this open-access publication were covered by the Max Planck Society.

Review statement. This paper was edited by Corinna Hoose and reviewed by two anonymous referees.

\section{References}

Allen, M. R. and Ingram, W. J.: Constraints on future changes in climate and the hydrologic cycle, Nature, 419, 224-232, 2002.

Ban, N., Schmidli, J., and Schär, C.: Evaluation of the convectionresolving regional climate modeling approach in decadelong simulations, J. Geophys. Res.-Atmos., 119, 7889-7907, https://doi.org/10.1002/2014JD021478, 2014.
Ban, N., Schmidli, J., and Schär, C.: Heavy precipitation in a changing climate: Does short-term summer precipitation increase faster?, Geophys. Res. Lett., 42, 1165-1172, 2015.

Bartels, H., Weigl, E., Reich, T., Lang, P., Wagner, A., Kohler, O., and Gerlach, N.: Projekt RADOLAN - Routineverfahren zur Online-Aneichung der Radarniederschlagsdaten mit Hilfe von automatischen Bodennierderschlagsstationen (Ombrometer), Technical Report, Deutscher Wetterdienst, Offenbach, Germany, 2004 (in German).

Benkrid, K. and Crookes, D.: Design and FPGA Implementation of a Perimeter Estimator, available at: http://www.cs.qub.ac.uk/ d. crookes/webpubs/papers/perimeter.doc, last access: 2017.

Berg, P., Moseley, C., and Haerter, J. O.: Strong increase in convective precipitation in response to higher temperatures, Nat. Geosci., 6, 181-185, 2013.

Bryan, G. H., Wyngaard, J. C., and Fritsch, J. M.: Resolution requirements for the simulation of deep moist convection, Mon Weather Rev., 131, 2394-2416, https://doi.org/10.1175/15200493(2003)131<2394:RRFTSO>2.0.CO;2, 2003.

Dipankar, A., Stevens, B., Heinze, R., Moseley, C., Zängl, G., Giorgetta, M., and Brdar, S.: Large eddy simulation using the general circulation model ICON, J. Adv. Model. Earth Sy., 7, 963-986, https://doi.org/10.1002/2015MS000431, 2015.

Dixon, M. and Wiener, G.: TITAN: Thunderstorm Identification, Tracking, Analsyis, and Nowcasting - A Radar-based Methodology, J. Atmos. Ocean. Tech., 1993, 785-797, 1993.

Emori, S. and Brown, S. J.: Dynamic and thermodynamic changes in mean and extreme precipitation under changed climate, Geophys. Res. Lett., 32, L17706, https://doi.org/10.1029/2005GL023272, 2005.

Fiolleau, T. and Roca, R.: An Algorithm for the Detection and Tracking of Tropical Mesoscale Convective Systems Using Infrared Images From Geostationary Satellite, IEEE T. Geosci. Remote, 51, 4302-4315, https://doi.org/10.1109/TGRS.2012.2227762, 2013.

Haerter, J. O., Böing, S. J., Henneberg, O., and Nissen, S. B.: Circling in on Convective Organization, Geophys. Res. Lett., 46, 7024-7034, https://doi.org/10.1029/2019GL082092, 2019.

Heiblum, R. H., Altaratz, O., Koren, I., Feingold, G., Kostinski, A. B., Khain, A. P., Ovchinnikov, M., Fredj, E., Dagan, G., Pinto, L., Yaish, R., and Chen, Q.: Characterization of cumulus cloud fields using trajectories in the center of gravity versus water mass phase space: 1 . Cloud tracking and phase space description, J. Geophys. Res.-Atmos., 121, 6336-6355, https://doi.org/10.1002/2015JD024186, 2016.

Heinze, R., Dipankar, A., Henken, C. C., Moseley, C., Sourdeval, O., Trömel, S., Xie, X., Adamidis, P., Ament, F., Baars, H., Barthlott, C., Behrendt, A., Blahak, U., Bley, S., Brdar, S., Brueck, M., Crewell, S., Deneke, H., Di Girolamo, P., Evaristo, R., Fischer, J., Frank, C., Friederichs, P., Göcke, T., Gorges, K., Hande, L., Hanke, M., Hansen, A., Hege, H.-C., Hoose, C., Jahns, T., Kalthoff, N., Klocke, D., Kneifel, S., Knippertz, P., Kuhn, A., van Laar, T., Macke, A., Maurer, V., Mayer, B., Meyer, C. I., Muppa, S. K., Neggers, R. A. J., Orlandi, E., Pantillon, F., Pospichal, B., Röber, N., Scheck, L., Seifert, A., Seifert, P., Senf, F., Siligam, P., Simmer, C., Steinke, S., Stevens, B., Wapler, K., Weniger, M., Wulfmeyer, V., Zängl, G., Zhang, D., and Quaas, J.: Large-eddy simulations over Germany using ICON: a com- 
prehensive evaluation, Q. J. Roy. Meteor. Soc., 143, 69-100, https://doi.org/10.1002/qj.2947, 2017.

Hering, A., Senesi, S., Ambrosetti, P., and Bernard-Bouissieres, I.: Nowcasting thunderstorms in complex cases using radar data, WWRP Symbosium on Nowcasting and Very Short Range Forecasting, 5-9 September 2005, Toulouse, 2.14, 2005.

Heus, T. and Seifert, A.: Automated tracking of shallow cumulus clouds in large domain, long duration large eddy simulations, Geosci. Model Dev., 6, 1261-1273, https://doi.org/10.5194/gmd6-1261-2013, 2013.

Hirt, M., Craig, G. C., Schäfer, S. A. K., Savre, J., and Heinze, R.: Cold pool driven convective initiation: Using causal graph analysis to determine what km-scale models are missing, Q. J. Roy. Meteor. Soc., in review, 2020.

Kendon, E. J., Roberts, N. M., Fowler, H. J., Roberts, M. J., Chan, S. C., and Senior, C. A.: Heavier summer downpours with climate change revealed by weather forecast resolution model, Nat. Clim. Change, 4, 570-576, 2014.

Klocke, D., Brueck, M., Hohenegger, C., and Stevens, B.: Rediscovery of the doldrums in storm-resolving simulations over the tropical Atlantic, Nat. Geosci., 10, 891-896, https://doi.org/10.1038/s41561-017-0005-4, 2017.

Kober, K. and Tafferner, A.: Tracking and nowcasting of convective cells using remote sensing data from radar and satellite, Meteorol. Z., 18, 75-84, https://doi.org/10.1127/0941-2948/2009/359, 2009.

Langhans, W., Schmidli, J., and Schär, C.: Bulk Convergence of Cloud-Resolving Simulations of Moist Convection over Complex Terrain, J. Atmos. Sci., 69, 2207-2228, https://doi.org/10.1175/JAS-D-11-0252.1, 2012.

Lenderink, G. and Van Meijgaard, E.: Increase in hourly precipitation extremes beyond expectations from temperature changes, Nat. Geosci., 1, 511-514, 2008.

Lochbihler, K., Lenderink, G., and Siebesma, A. P.: The spatial extent of rainfall events and its relation to precipitation scaling, Geophys. Res. Lett., 44, 8629-8636, https://doi.org/10.1002/2017GL074857, 2017.

Louis, J.-F.: A parametric model of vertical eddy fluxes in the atmosphere, Bound.-Lay. Meteorol., 17, 187-202, https://doi.org/10.1007/BF00117978, 1979.

Moseley, C. and Haerter, J. O.: Iteractive Rain Cell Tracking Code, available at: https://github.com/christophermoseley/ iterative_raincell_tracking, last access: 28 February 2020.

Moseley, C. and Pscheidt, I.: Postprocessing and plotting scripts for results reproduction, archived by the Max Planck Institute for Meteorology, available at: http://hdl.handle.net/21.11116/ 0000-0004-8662-6, last access: 28 February 2020.

Moseley, C., Hohenegger, C., Berg, P., and Haerter, J. O.: Intensification of convective extremes driven by cloud - cloud interaction, Nat. Geosci., 9, 748-752, 2016.

Moseley, C., Henneberg, O., and Haerter, J. O.: A Statistical Model for Isolated Convective Precipitation Events, J. Adv. Model. Earth Sy., 11, 360-375, https://doi.org/10.1029/2018MS001383, 2019.

Nair, U., Weger, R., Kuo, K., and Welch, R.: Clustering, randomness, and regularity in cloud fields. 5. The nature of regular cumulus cloud fields, J. Geophys. Res., 103, 11363-11380, 1998.

Neggers, R. A. J., Griewank, P. J., and Heus, T.: Power-Law Scaling in the Internal Variability of Cumulus Cloud Size Distributions due to Subsampling and Spatial Organization, J. Atmos. Sci., 76, 1489-1503, https://doi.org/10.1175/JAS-D-18-0194.1, 2019.

Norris, J., Chen, G., and Neelin, J. D.: Thermodynamic versus Dynamic Controls on Extreme Precipitation in a Warming Climate from the Community Earth System Model Large Ensemble, J. Climate, 32, 1025-1045, https://doi.org/10.1175/JCLI-D18-0302.1, 2019.

Panosetti, D., Schlemmer, L., and Schär, C.: Bulk and structural convergence at convection-resolving scales in real-case simulations of summertime moist convection over land, Q. J. Roy. Meteor. Soc., https://doi.org/10.1002/qj.3502, 2019.

Petch, J., Brown, A., and Gray, M.: The impact of horizontal resolution on the simulations of convective development over land, Q. J. Roy. Meteor. Soc., 128, 2031-2044, https://doi.org/10.1256/003590002320603511, 2002.

Pfahl, S., O'Goreman, P. A., and Fischer, E. M.: Understanding the regional pattern of projected future changes in extreme precipitation, Nat. Clima. Change, 7, 423-427, https://doi.org/10.1038/nclimate3287, 2017.

Piper, D., Kunz, M., Ehmele, F., Mohr, S., Mühr, B., Kron, A., and Daniell, J.: Exceptional sequence of severe thunderstorms and related flash floods in May and June 2016 in Germany - Part 1: Meteorological background, Nat. Hazards Earth Syst. Sci., 16, 2835-2850, https://doi.org/10.5194/nhess-16-2835-2016, 2016.

Pritchard, M. S. and Somerville, R. C. J.: Assessing the Diurnal Cycle of Precipitation in a Multi-Scale Climate Model, J. Adv. Model. Earth Sys., 1, 12, https://doi.org/10.3894/JAMES.2009.1.12, 2009.

Pscheidt, I., Senf, F., Heinze, R., Deneke, H., Trömel, S., and Hohenegger, C.: How organized is deep convection over Germany?, Q. J. R. Meteor. Soc., 145, 2366-2384, https://doi.org/10.1002/qj.3552, 2019.

Rasp, S., Selz, T., and Craig, G. C.: Variability and Clustering of Midlatitude Summertime Convection: Testing the Craig and Cohen Theory in a Convection-Permitting Ensemble with Stochastic Boundary Layer Perturbations, J. Atmos. Sci., 75, 691-706, https://doi.org/10.1175/JAS-D-17-0258.1, 2018.

Ruppert, J. H. and Hohenegger, C.: Diurnal Circulation Adjustment and Organized Deep Convection, J. Climate, 31, 4899-4916, https://doi.org/10.1175/JCLI-D-17-0693.1, 2018.

Schrodin, R. and Heise, E.: A new multi-layer soil model, COSMO Newsletter, 2, 149-151, 2002.

Senf, F., Klocke, D., and Brueck, M.: Size-Resolved Evaluation of Simulated Deep Tropical Convection, Mon. Weather Rev., 146, 2161-2182, 2018.

Singh, M. S. and O'Gorman, P. A.: Influence of microphysics on the scaling of precipitation extremes with temperature, Geophys. Res. Letts, 41, 6037-6077, 2014.

Stevens, B., Satoh, M., Auger, L., Biercamp, J., Bretherton, C. S., Chen, X., Dueben, P., Judt, F., Khairoutdinov, M., Klocke, D., Kodama, C., Kornblueh, L., Lin, S.-J., Putman, W. M., Shibuya, R., Neumann, P., Roeber, N., Vanniere, B., Vidale, P.-L., Wedi, N., and Zhou, L.: DYAMOND: The DYnamics of the Atmospheric general circulation Modeled On Non-hydrostatic Domains, Prog. Earth Planet. Sci., 6, 61, https://doi.org/10.1186/s40645-019-0304-z, 2019.

Tobin, I., Bony, S., and Roca, R.: Observational evidence for Relationships between the Degree of Aggregation of Deep Convec- 
tion, Water Vapor, Surface Fluxes, and Radiation, J. Climate, 25, 6885-6904, 2012.

Tompkins, A. and Semie, A.: Organization of tropical convection in low vertical wind shears: Role of updraft entrainment, J. Adv. Model. Earth Sy., 9, 1046-1068, https://doi.org/10.1002/2016MS000802, 2017.

Trenberth, K. E., Dai, A., Rasmussen, R. M., and Parsons, D. B.: The changing character of precipitation, B. Am. Meteorol. Soc., 84, 1205-1218, 2003.

van der Walt, S., Schönberger, J., Nunez-Iglesias, J., Boulogne, F., Warner, J., Yager, N., Gouillart, E., Yu, T., and and the scikitimage contributors: scikit-image: image processing in Python, https://doi.org/10.7717/peerj.453, 2014.

van Stratum, B. J. H. and Stevens, B.: The influence of misrepresenting the nocturnal boundary layer on idealized daytime convection in large-eddy simulation, J. Adv. Modeli. Earth Sy., 7, 423-436, https://doi.org/10.1002/2014MS000370, 2015.
Wapler, K.: The life-cycle of hailstorms: Lightning, radar reflectivity and rotation characteristics, Atmos. Res., 193, 60-72, https://doi.org/10.1016/j.atmosres.2017.04.009, 2017.

Weger, R., Lee, J., Zhu, T., and Welch, R.: Clustering, Randomness and Regularity in Cloud Fields: 1. Theoretical Considerations, J. Geophys. Res., 97, 20519-20536, 1992.

Westra, S., Fowler, H., Evans, J., Alexander, L., Berg, P., Johnson, F., Kendon, E., Lenderink, G., and Roberts, N.: Future changes to the intensity and frequency of short-duration extreme rainfall, Rev. Geophys., 52, 522-555, 2014.

White, B., Buchanan, A., Birch, C., Stier, P., and Pearson, K.: Quantifying the Effects of Horizontal Grid Length and Parameterized Convection on the Degree of Convective Organization Using a Metric of Potential for Convective Interation, J. Atmos. Sci., 75, 425-450, https://doi.org/10.1175/JAS-D-16-0307.1, 2018. 